\title{
STATUS AND OUTLOOK FOR THE SPACE COMPONENT OF AN INTEGRATED OCEAN OBSERVING SYSTEM
}

\author{
Mark R. Drinkwater ${ }^{(1)}$, Hans Bonekamp ${ }^{(2)}$, Paula Bontempi ${ }^{(3)}$, Bertrand Chapron ${ }^{(4)}$, Craig Donlon ${ }^{(1)}$, Jean-Louis \\ Fellous ${ }^{(5)}$, Paul DiGiacomo ${ }^{(6)}$, Ed Harrison ${ }^{(7)}$, Pierre-Yves LeTraon $^{(8)}$, Stan Wilson ${ }^{(9)}$ \\ ${ }^{(1)}$ European Space Agency, ESTEC, Keplerlaan 1, NL-2201 AZ Noordwijk, The Netherlands, \\ Email: mark.drinkwater@esa.int \\ ${ }^{(2)}$ EUMETSAT, Eumetsat-Allee 1, 64295 Darmstadt, Germany, Email: hans.bonekamp@eumetsat.int \\ ${ }^{(3)}$ NASA HQ, MS 3B74, 300 E St. SW, Washington, DC 20546, U.S.A., Email: paula.s.bontempi@nasa.gov \\ (4) IFREMER, Centre de Recherche et d'Exploitation Satellitaire, Pointe du Diable 29280 Plouzane, France, \\ Email: Bertrand.Chapron@ifremer.fr \\ ${ }^{(5)}$ COSPAR clo CNES, 2 Place Maurice-Quentin, 75039 Paris Cedex 01, France, \\ Email:jean-louis.fellous@cosparhq.cnes.fr \\ (6) NOAA/NESDIS/STAR, 5200 Auth Road, Camp Springs, MD 20746, U.S.A, Email: Paul.DiGiacomo@noaa.gov

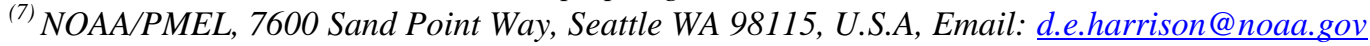 \\ ${ }^{(8)}$ IFREMER, Centre de Brest B.P. 70 29280, Plouzané France, Email: Pierre.Yves.Le.Traon@ifremer.fr \\ ${ }^{(9)}$ NOAA/NESDIS, 1335 East West Highway, Silver Spring, MD 20910, U.S.A, \\ Email: stan.wilson@noaa.gov
}

\begin{abstract}
The space component of the global ocean observing system developed and matured remarkably over the last decade. Solid progress was made towards a more coherent and internationally-coordinated satellite infrastructure through effective scientific and political advocacy and international coordination. This has allowed the design and development of a number of mature operational systems delivering systematic and robust long-term measurements, coupled with a suite of complementary scientific satellite elements that feed innovative new measurement capabilities into the observing system infrastructure. Together with the insitu system elements, these form a solid foundation for an integrated global observing system of systems of the future - to serve both research and operational interests. In spite of the relative success over the last decade, significant challenges remain for the next decade. The burgeoning expense of sustaining critical global satellite measurement data-streams dictates that tools and methods must be developed to remove redundancies, to further optimise the satellite infrastructure, and to better link complementary observing system elements. Efforts to engage involve and integrate satellite data streams of new participating space agencies, and furthering the ideal of free and open data exchange will be rewarded by product synergies and vital added-value. Meanwhile, all such efforts must be underpinned by widespread promotion and adoption of standards-based bestpractices, including rigorous data calibration and product validation, proven methods of quality control, and flagging of data quality and quantitative estimates of measurement uncertainties. The latter is of absolute importance to maximise the use of data products in model data assimilation schemes, to improve ocean state
\end{abstract}

estimates and forecasting capabilities. As with numerical weather prediction, improved 3-D state estimation is a foundation for development of sustainable services and initialisation of seasonal to interannual, and climate and Earth system forecasting models.

\section{INTRODUCTION}

Understanding the ocean-related aspects of the Earth system, including weather, climate, water cycle, natural resources, ecosystems, and natural and human-induced hazards, is crucial to achieving sustainable development, and to protecting humankind and the global environment. Satellite observations of the Earth system are recognised as a fundamental input for advancing this understanding.

During the last decade we have often heard the words, "we are in the Golden Age of satellite oceanography". Indeed satellite oceanography has become a truly international endeavour. Since the OceanObs'99 meeting, the ocean community has witnessed the launch of over 30 new ocean-related satellite missions with dedicated ocean instruments by 13 different contributing space agencies representing around 36 countries [1 and 2]. These satellites currently provide tens of millions of quality controlled measurements each day that are assimilated into various operational numerical weather and ocean prediction models. They are also used in initialising representative contemporary conditions for climate, carbon cycle, and ecosystem model forecasts. The basic geophysical data products, together with the resulting model state estimates or analyses, are fundamental to improving scientific understanding in the fields of physical oceanography, ocean biology and 
biogeochemistry, cryospheric science, and related climate research.

Plans for new satellites with ocean sensors are already developed and current investments are already focusing on delivery of new systems in the post-2020 time frame. If we consider the next decade through 2020, the launch of approximately 14 new approved operational and research and development ocean-related satellite missions are planned. These satellites and their ocean instruments are in various stages of development, and thus the ocean community must be engaged in preparations for the data applications in order to most effectively benefit from their new data products.

Today it is evident that the ocean community will have access to an exciting and well equipped space infrastructure seen as a component of the integrated Global Earth Observation System of Systems (GEOSS). Successive key contributions of ocean-related satellites from new space-faring organisations and countries boost the potential of the system to an unprecedented level. But, in order to harness the full capability and benefit of this complex system there are challenges which must be overcome. For instance, the satellite infrastructure is reliant upon external calibration and validation with respect to independent data provided by in situ and other sampling systems that make up the other parts of the ocean observing system. Such efforts must be carefully coordinated, with standards and tried and best practice methodologies applied to assure quality. In particular, satellite products must be accompanied by quality indicators and quantitative estimates of measurement uncertainty. Finally, free, open and timely data access and sharing under GEOSS principles is still a significant challenge, although some progress is being made in this area.

From a broad perspective, the space-based component of the integrated global ocean observing system is, and will continue to be a critical component of the GEOSS. In order to be sustainable, it must continue to develop and be increasingly tuned to issues of societal benefit, as a fundamental basis for maximizing the relevance of contributions of satellite observations. The socioeconomic benefits are increasingly becoming a metric by which to justify the expense of maintaining or sustaining such a complex system.

This paper addresses the evolution of the requirements approach and the lessons learned along the way towards implementing the current infrastructure. New methods for optimising the existing system infrastructure are proposed, together with outlining the plans for use of forthcoming new satellite datasets. Finally, some of the main challenges are outlined for the next decade.
This Plenary Paper draws extensively on the following Plenary and Community White Papers: $[3,4,5,6,7,8$, 9, 10, 11, 12, 13, 14, 15, 16, 17 and 79].

\section{EVOLUTION IN THE SPACE BASED OCEAN OBSERVING SYSTEM}

Over the last decade, requirements for ocean satellites have been consolidated and aligned with a broad range of user needs. Experience has taught the various international Space Agencies that it is most effective to establish firm user requirements [18] before building political consensus for a new satellite mission, or a sustained series of missions around them. A number of developments over the last decade have been fundamental in space agencies establishing the appropriate arguments for the required elements of the space component of the ocean observing system. These are documented in the sections below.

\subsection{Progressive Consolidation of User Requirements}

The global interest in Oceanography and Marine Meteorology encompasses a wide range of users that need routine access to accurate knowledge on the present state of the ocean and the atmosphere above, and the terrestrial environment with which it interacts. Broadly speaking there are critical requirements for uniform, global ocean data products that reinforce the capacity for:

- Numerical Weather Prediction

- Numerical Ocean Prediction

- Climate Research, and Climate Services

- Maritime Safety \& Met-Ocean and Ice Forecasting

- Advanced marine research for better quantification and understanding of the oceans, ocean margins, large lakes and inland seas, and their ecosystems and biogeochemical cycling

- Sustainable utilisation and management of ocean resources (e.g. ecosystems for recreation and public health, fisheries, offshore oil and gas industry)

- Anticipation and mitigation of the effects of natural and anthropogenic environmental hazards (e.g. coastal erosion, coastal flooding, eutrophication, and pollution events including oil spills, harmful algal blooms and terrestrial run off, etc.)

- Global carbon monitoring and carbon management (e.g., cap and trade, verification of ocean carbon sequestration)

- Environment Agency needs (e.g. European Environment Agency - EEA, Environmental Protection Agency - EPA, etc.)

- International Treaty and Convention enforcement (e.g. Safety of Life at Sea - SOLAS, London 
Convention, United Nations Convention on Law of the Sea - UNCLOS, etc.)

It is clear that the above user requirements span a variety of operational, research, and policy needs that themselves are interdependent. Perhaps the most pervasive development of the last decade is the acknowledgement that satellite missions must directly respond to areas of societal benefits in order for the costly infrastructure to be justifiable and sustainable. The GEOSS Implementation Plan (2005-2015) clearly identifies the need to deliver of benefits to society [19], in several areas where the ocean services listed above are directly relevant:

- Reducing loss of life and property from natural and human-induced disasters;

- Understanding environmental factors affecting human health and well-being;

- Improving management of energy resources;

- Understanding, assessing, predicting, mitigating, and adapting to climate variability and change;

- Improving water resource management through better understanding of the water cycle;

- Improving weather information, forecasting, and warning of extreme events;

- Improving the management and protection of terrestrial, coastal, and marine ecosystems, and;

- Understanding, monitoring, and conserving biodiversity.

The satellite system component must therefore meet the need for timely, quality long-term global information as a basis for sound decision making and socio-economic benefits.

\subsection{Sustained Climate Monitoring}

Although almost all Earth-observing satellite systems were not specifically designed for climate monitoring, space-agency efforts have initiated a remarkably comprehensive set of climate data records that form the basis for improved understanding the Earth's climate system.

In terms of the climate observing needs, the Global Climate Observing System (GCOS) Implementation Plan and plan for systematic satellite data for climate [20 and 21] is a significant step towards establishing a consolidated roadmap. These documents reinforce the fact that satellites provide a means of obtaining climaterelevant, uniform, global, ocean observations, and a detailed climate record for the future will not be possible without a sustained, satellite component. This is due to the enhanced spatial and temporal coverage offered by satellite instruments, and the long-term stability and monitoring provided over the global ocean.
They further identify that for satellites to contribute fully and effectively to the determination of long-term data records, the system must be implemented and operated in an appropriate manner to ensure that the data are robust, accurate and homogeneous. To this end, the common-sense GCOS Climate Monitoring Principles [20] call for continuity of observations, calibration and validation of observations, access to data, and research and development. Together these form the foundation for fundamental climate data records.

Though much has clearly been accomplished, more remains to be done, especially in mitigating gaps in critical measurement capabilities in order to maintain their continuity through planned overlap of missions. Meanwhile, the Committee on Earth Observing Satellites (CEOS) response to the GCOS Implementation Plan [22] outlines a comprehensive list of actions that various Agencies are currently undertaking to ensure that the GCOS requirements are met.

\subsection{Maturation of Numerical Ocean Prediction and Ocean Data Assimilation}

Over the past decade, there have been major advances in the way in situ and remote sensing data are used together with models in data assimilation systems. The routine availability of satellite datasets has allowed operational ocean forecasting to flourish [23]. The Global Ocean Data Assimilation Experiment (GODAE), proposed in 1997 [7], has been fundamental in galvanising community-wide efforts towards bringing ocean forecasting based on Numerical Ocean Prediction (NOP) to a credible, operational state - in which the benefits of real-time global ocean data assimilation and forecasting are now routinely demonstrated. In particular, GODAE provided a fundamental impetus for effective use of satellite data in forecasting systems. In turn this has helped the satellite agencies to establish firm requirements for products, product timeliness, and access - as well as driving new requirements for data product quality flags and validated bounds of uncertainty [5].

In-situ and remote sensing data delivered in near real time are now routinely assimilated in global ocean models [23] to provide an integrated description and forecast of the ocean state [24], as well as providing boundary conditions to numerical weather forecast models. Different assimilation techniques and model resolutions are used depending on applications (e.g. climate or mesoscale). While some operational applications or research activities can rely on the data products themselves, this integrated description is a powerful means to take full advantage of the different observing systems. The use of models as dynamical 
interpolators provides improved description of the observed variables, estimates of parameters that are not directly observed and forecasts of the ocean state. This is required for most of the applications. High resolution ocean surface topography (OST), sea surface temperature (SST), ocean vector winds (OVW), ocean colour radiometry (OCR) sea ice concentration (SIC) and ocean salinity (SSS) are the main data sets used today to constrain global ocean models (see Fig. 1). Meanwhile, there are a number of additional new datasets that have become commonly available that allow further development in hydrodynamic and sea ice parameterisations, as well biogeochemical processes.

As a consequence of GODAE, a large number of operational and research institutions around the world [7] are now providing regular, global and regional analyses and forecasts of ocean fields such as temperature, salinity and currents at high temporal and spatial resolution. Throughout GODAE, numerical assimilation methodologies have been significantly improved to make the best use of satellite remote sensing together with in-situ data. In parallel, links with intermediate users and applications have been developed: maritime safety (e.g. oil pollution monitoring), offshore applications, fishery management, boundary conditions for coastal and regional subsystems, naval operations, and initial conditions of weather and climate forecast models. Global ocean analyses are also used for an improved understanding of the oceans and as a basis for improving the design and effectiveness of the global ocean observing system. Together with the Integrated Global Observing Strategy Partnership (IGOS-P) Ocean Theme Team report [25], the GODAE developments have provided a fundamental justification for implementation of a global ocean observing system including the requisite space-based observable parameters in Fig. 1.

\subsection{An Ocean Component of an Integrated Global Observing System}

The Integrated Global Observing Strategy Partnership was established in 1998 as a means of bringing the need for a coherent and comprehensive integrated approach to sustained observations of the global ocean to the attention of the Committee on Earth Observing Satellites (CEOS). The IGOS-P Ocean Theme Report was published in January 2001 [25]. This report was the first in which the in situ observing community, largely represented by the open ocean/climate component of the Global Ocean Observing System (GOOS) and Global Climate Observing System (GCOS), joined forces with the satellite remote sensing measurement community to produce a series of consolidated statements about the priority observations. The report was developed on the foundation of the developments in GOOS, together with the reports of the OceanObs'99 conference [26, 27]. The content of the document has undoubtedly influenced the approach of CEOS and of the agencies that are its members, especially in making the case for certain types of space-based observation and in underlining the importance of continuity of measurements.

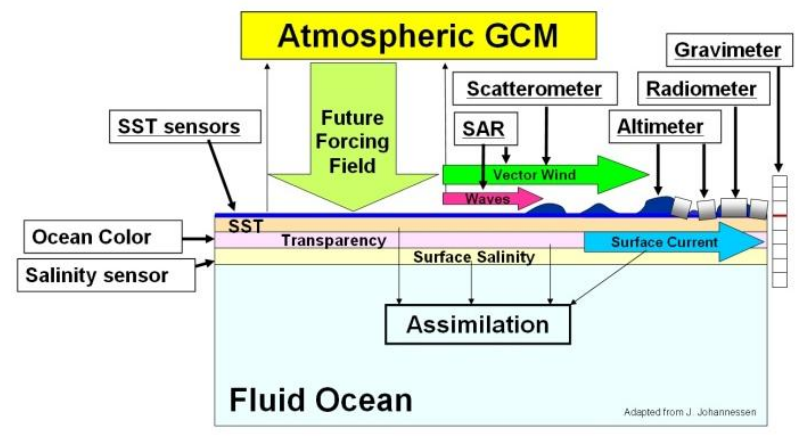

Figure 1. Basic observation parameters required for routine model data assimilation and operational oceanography.

It is difficult to fully quantify the impact of the Ocean Theme Report, but it does seem clear that it established the justification for a number of key decisions in the subsequent years. Altimetry, SAR and salinity remote sensing have arguably seen the most consolidation of their position, though ocean vector winds observation and ocean colour radiometer mission developments are relatively less secure. One critical issue for climate remains with the recent descope of the all-weather SST instrument capability from NPOESS (National Polarorbiting Operational Environmental Satellite System renamed the Joint Polar Satellite System or JPSS), as well as the potential for a break in continuity of climate quality ocean colour radiometry data. Despite new allweather SST instruments aboard the Japan Aerospace Exploration Agency Global Change Observation Mission - Water (JAXA GCOM-W) series, the lack of a long-term commitment to all weather passive microwave SST represents a key weakness in terms of robustness of anticipated satellite observation capabilities.

A key success story has been the transition of precision satellite altimetry from research to operations. The Jason-1 successor to TOPEX/Poseidon (T/P), was flown as a partnership of the U.S. and France, while the partnership was extended for the follow-on mission Jason-2, to include the U.S. National Oceanic and Atmospheric Administration (NOAA) and European Organisation for the Exploitation of Meteorological Satellites (Eumetsat) operational agencies. Currently, a full operational transition is approved for a recurrent Jason-3 with NOAA and Eumetsat taking full 
responsibility for financing. Meanwhile, the successor to Jason-3, in the form of Jason-CS (i.e. based on the CryoSat platform and altimeter technology) is currently being treated as part of the European contribution to the operational observing system infrastructure.

The "knowledge challenge" in the Ocean Theme Report [25] related to measurement of sea surface salinity and gravity from space was taken up by the CEOS agencies. Two fundamentally new L-band radiometer missions, SMOS (Soil Moisture and Ocean Salinity) and Aquarius were planned to make the first salinity observations from space. In meeting these challenges, SMOS was recently successfully launched in November 2009 [28] while Aquarius is planned for launch in late 2010.

Similarly, the challenge to make gravity measurements to improve the ocean geoid and to study mass redistribution has been met, with the consecutive launches of the CHAMP (CHAllenging Mini-Satellite Payload), GRACE (Gravity Recovery And Climate Experiment) and GOCE (Gravity and Steady State Ocean Circulation Explorer) satellites. The first of these two missions have contributed to successively improving the geoid (hypothetical surface corresponding to the ocean at rest) to $1 \mathrm{~cm}$ accuracy at a scale of $400 \mathrm{~km}$, with GOCE promising to achieve the goal of a 1-2 cm accuracy geoid at $100 \mathrm{~km}$ wavelength scales.

The Ocean Theme team report undoubtedly also helped to encourage investment in the development of the Global Ocean Data Assimilation Experiment (GODAE), which by 2001 had gathered momentum. The document highlighted that GODAE was essential to establish the capability to integrate and assimilate the in situ and the remotely sensed data streams into advanced numerical models in order to produce maps and forecasts of ocean properties and, ultimately, of climate change.

More recently, the IGOS-P Coastal Theme Report [29] identified additional space-based and in situ observing system requirements specifically tailored for coastal regions, particularly the need for improved spatial, temporal and spectral resolution of physical, biological, biogeochemical and ecological observations (e.g., geostationary, hyperspectral ocean colour). Some of the missions and new capabilities described below are beginning to address some of the significant challenges and requirements in effectively observing coastal regions.

IGOS-P (Integrated Global Observing StrategyPartnership) has demonstrated that partnerships are a necessary condition for the successful transition of measurements from research (initial demonstration) to operations (characterised by routine, systematic, and long-term measurements). Another lesson learned from the Ocean and Coastal Theme Reports [25, 29] is that a high-level synthesis of observing requirements and capabilities for policy makers should be undertaken every 5 years or so. The disciplines that are ultimately able to construct such a synthesis internationally, across a suite of observations, will likely be able to advance their cause more effectively and successfully.

\subsection{Transition of the IGOS Partnership into GEOSS Framework}

The World Summit on Sustainable Development held in Johannesburg in 2002 called for strengthened cooperation and coordination among global observing systems and research programmes to produce an integrated set of global observations. The outcome of the subsequent G-8 Summit held in Evian in June 2003 similarly called for strengthened international cooperation on global observation of the environment.

As a consequence of these meetings, thirty-three nations and the European Commission gathered in Washington D.C. on July 31,2003 , for the $1^{\text {st }}$ Earth Observation Summit. A declaration was established that called for action in strengthening global cooperation on Earth observation was adopted. The Summit participants launched the intergovernmental ad hoc Group on Earth Observations with the goal of furthering the creation of the GEOSS. The group began its work by establishment of its first 10-year Implementation Plan [19].

Subsequently, in November 2006 at the IGOS-P meeting in Buenos Aires, CEOS proposed to integrate the IGOS partnership into GEO (Group on Earth Observations). Implementation of the IGOS-P Ocean Theme and its observation strategy was formally transferred into the GEOSS framework with coordination from GEO. With this transformation comes the promise of greater political visibility and more prominent advocacy for the required ocean observing system elements.

\subsection{Development of Operational Oceanography}

The establishment of a political framework for GEOSS and the accompanying Earth Observation Summits have been the backdrop to the establishment of a significant European contribution to GEOSS. The Global Monitoring for Environment and Security (GMES) initiative has been established in the course of the last decade to fulfill the growing need amongst European policy-makers to access accurate and timely information to better manage the environment, understand and mitigate the effects of climate change and ensure civil security. Under the leadership of the European Commission, GMES relies to a significant degree on data from Earth observing satellites. 
The European Commission, acting on behalf of the European Union (EU), is responsible for the overall initiative, setting requirements and managing the services. Meanwhile, the European Space Agency (ESA) - in accordance with the European Space Policy - is developing and managing the Space Component for the initiative. To ensure the operational provision of Earth-observation data, the Space Component includes a series of space missions called 'Sentinels', which are being developed by ESA specifically for GMES. Importantly, GMES responds directly to the needs of the ocean observing system, with one of its missions, Sentinel-3 [64], dedicated to global ocean observations. Data from satellites that are already in orbit, or are planned, will also be used for the initiative. These socalled 'Contributing Missions' are owned and operated at European level by the EU, ESA, EUMETSAT and their Member States, or on a national basis. This may also include data acquired from non-European partners.

Operational oceanography and sustainable services to environmental stakeholders and downstream applications will be the main goals of the GMES Marine Core Service (MCS) which is currently being built up as part of this initiative. The MyOcean project [30], selected for implementation of the numerical Ocean Prediction component of GMES MCS, gathers a large number of European contributors [31]. It aims at developing this operational capacity, based on continuous high-accuracy observations. A major component of the global set of ocean measurements is foreseen to be provided by dedicated ocean satellite missions.

In the United States (U.S.), satellite observations are also recognized to be a key component of the Integrated Ocean Observing System [32], the U.S. contribution to the GOOS. In this broader context, and as described later, satellite systems and observations are increasingly moving from the realm of the successful research and development (R\&D) efforts of NASA and becoming operational within NOAA and other agencies to provide measurement continuity and support for user applications and associated data and information needs (e.g. NPOESS Preparatory Project, JPSS, and Jason-3).

\section{THE STATE OF THE SPACE COMPONENT}

The current state of the space-based infrastructure is outlined briefly in the following sections.

\subsection{Maturation of Observing System Elements}

Since 1999 there has been significant attention given to establishing the space-based component of the ocean observing system. The satellite observing system priorities outlined at OceanObs'99 [26] and in the
IGOS-P Ocean Theme report [25] have been incrementally treated, such that most of the priority variables are covered, albeit with varying degrees of long-term sustainability. Many of the knowledge challenges identified at that time [25] are well on the way to being addressed due to realisation of some of the new technologies and satellite concepts that were only in their infancy at the end of the 1990's [27]. The following sections briefly describe the status of the key variables.

\subsubsection{Ocean Surface Topography (OST)}

Due to the expense and the logistical difficulty of obtaining global in-situ measurements, altimeter ocean surface topography data are identified as one of the most critical measurement datasets for ocean, climate and operational oceanography applications. The current vision for the CEOS Ocean Surface Topography Virtual Constellation [3] outlines a recommended observation strategy relying on two components: (1) at least one high-precision reference altimeter mission satisfying the climate-quality sea-level requirement, with orbit and coverage ensuring that data are free of tidal aliasing (e.g. Jason-type); and (2) at least two, and preferably 3, additional altimetry systems flying on orbits optimised to obtain global coverage (e.g. ENVISAT/RA2, CryoSat-2/SIRAL, SARAL/AltiKa, HY-2, Sentinel3/SRAL, Geosat Follow-On-2) with an orbit cross-over density sufficient for addressing mesoscale ocean applications.

The launch of Jason-1 in 2001 continued the series of sea-level reference missions established with $\mathrm{T} / \mathrm{P}$ in 1992. More recently, the Jason-2 launch in 2008 assured continuous reference measurements through 2012. The recently-secured Jason-3 programme guarantees continuity through 2020 and beyond. Meanwhile, planning is already underway to establish new platform technology to succeed the Jason-3 Proteus platform, with a successor based on CryoSat platform heritage and currently identified as Jason-CS.

Importantly, the complementary, series of highinclination orbiting altimeters has provided more dense global coverage with which to capture the mesoscale circulation thereby enabling the growth in operational oceanography applications. The ERS-1, ERS-2, Envisat, Geosat, and Geosat follow-on (GFO) missions have illustrated the benefits from their complementary with $\mathrm{T} / \mathrm{P}$ and Jason, through the synergetic data products of AVISO DUACS/SSALTO (see section 3.2 below).

With the approaching end of lifetime of Envisat, the addition of the joint Indian and French SARAL/AltiKa mission (on a similar orbit and Envisat/RA2 reference ground track) and HY-2 altimeter mission help to bridge until the start of the Sentinel-3A and -3B SRAL data timeseries. Both the SARAL and Sentinel-3 altimeters 
are equipped to provide high along-track resolution data, and will enable further developments in detecting sub-mesoscale features [33] and in coastal applications [13].

\subsubsection{Ocean Vector Winds (OVW)}

Measurements of ocean surface vector winds are needed for both operational NWP and climate purposes and are an increasingly important tool for wave forecasting and marine operations, and tropical cyclone warnings [4]. Over the last decade, the C-band ERS-2 wind scatterometer and Ku-band QuikSCAT (QSCAT) SeaWinds instruments have been the primary workhorses. Their combined operation has demonstrated that at least two scatterometers are required on well-separated orbits (ideally morning and evening) in order to ensure global provision of vector winds with a refresh cycle better than the existing six hour requirement. Whilst the $\mathrm{C}$-band scatterometer time-series (09:30hrs morning orbit) is secure with the European Metop (Meteorological Operational Satellite) mission, with the ASCAT (Advanced Scatterometer) series of operational instruments [15], the relatively broader- swath QSCAT SeaWinds instrument had long exceeded its design lifetime by the time it ceased operation on November 23, 2009. In the near-term, the loss of QSCAT means that the global routine operational provision of vector wind data is critically degraded to an approximately 24 hour refresh interval at any given location.

Wind vector data are also available from the WindSat polarimetric passive microwave demonstration instrument launched in 2003. It has been noted, however, that whilst the surface vector winds from passive instruments do provide additional global NWP input data, they do not fulfill the stringent requirements for climate quality vector winds [34]. Though providing meaningful data at high wind velocities, they exhibit significant limitations in the lower wind velocity range. Thus, in spite of the operational MIS instrument successor to WindSat - to be launched on NPOESS (JPSS) C3 in the 2020 timeframe - it is recognised that an operational successor to QSCAT/SeaWinds is needed to secure the necessary climate and global operational vector wind data stream.

The September 23, 2009 launch of the Indian Oceansat2 satellite with its SeaWinds-like Ku-band scatterometer, together with the planned 2011 launch of the first satellite in the Chinese HY-2 scatterometerequipped operational series, both potentially add vital supplementary global vector wind measurement capability. The combination of Metop/ASCAT, Oceansat-2 and HY-2A data would together ensure that the six-hourly refresh interval criteria can be met at latitudes of $35^{\circ}$ North of the equator. It is of critical importance that all space agencies flying scatterometers respond positively to recommendations from the recently established CEOS Ocean Surface Vector Wind Virtual Constellation (OVSW-VC) to make resulting data available without restriction and within a sufficiently timely manner that they can be used in operational marine forecasting [35].

Recent developments in fine resolution wind products from wide swath SAR instruments such as Envisat/ASAR can be used to supplement scatterometer wind data, albeit with a single narrower swath of $\sim 400 \mathrm{~km}$ in comparison to the twin $550 \mathrm{~km}$ swaths of the ASCAT scatterometer. These additional products in particular help in describing wind-wave coupling processes in extreme weather events, and facilitate additional new coastal applications where the resolution of scatterometer data is limited [4, 36]. Both the U.S. and Canada have initiated development projects for the operational implementation of coastal winds derived from SAR imagery. Both projects have operational implementation dates in 2011.

Meanwhile, planning is underway for the U.S. to develop a new generation dual frequency scatterometer (C- and $\mathrm{Ku}$-band) to be flown on the Japanese GCOMW2 and -W3 missions in 2016 and 2020 respectively.

\subsubsection{Sea State}

Sea state is critical to wind-wave coupling and surface fluxes (momentum, heat, water and gas), safety of marine operations and commercial use of the sea (ship routing, fisheries), and safety of coastal habitats [37]. Synthetic Aperture Radar (SAR) data today has the capability to measure wave height, period and direction, and to provide this operational information together with complementary winds and currents. Altimeters have traditionally delivered significant wave heights and wind speed, though of limited coverage along the subsatellite track. There remain perceived limitations as to the operational use and value of SAR, particularly due to the quality of the products co-varying with ocean and atmospheric conditions. Recently, new processing methods are supporting delivery of more robust coestimated wind/ wave/current information, and this gives more confidence in the quality of the retrievals.

Currently, operational sea-state information is available over wide areas in near-real time from ERS-2 SAR and Envisat ASAR, and is complemented by ERS-2 RA, Envisat RA2 and Jason-1 and Jason-2 altimeters. These sensors are supported by ASCAT and QSCAT scatterometer vector wind data for the met-ocean and modelling forecast communities. From a climate perspective, the roughness of the sea surface has greatest importance in terms of air-sea exchanges. It would be ideal to have full wave directional spectral capability spanning surface gravity wave and swell periods, though this is presently not feasible. 
Nonetheless, future Sentinel-1A, and 1B C-band SAR data should help to provide robust C-band time-series of directional wind/wave information.

\subsubsection{Sea Surface Temperature (SST)}

High-accuracy and high-resolution sea surface temperature observations are required for (i) NWP and in particular tropical cyclone forecasting; (ii) operational numerical ocean prediction; (iii) seasonal to interannual forecasting, and; (iv) marine and climate services [38]. Both Vis/IR and microwave data from a combination of polar orbiting satellites and geosynchronous orbiting satellites are equally important, one fulfilling the all-weather role, albeit at low resolution, and the other allows higher spatial and temporal resolution and in particular near coastal applications in locations where land contamination limits the use of microwave radiometers.

The typical split-window technique offered by IR radiometers such as AVHRR (NOAA and Metop), MODIS (Terra and Aqua) and VIRR (FY-3) is complemented by the dual-view, split window data provided by the (A)ATSR instruments on ERS-2 and Envisat, allowing improved atmospheric (including aerosol) corrections in both day/night surface temperature data and thus a highly accurate climatequality SST reference data source. Continuity will be provided in similar such measurements by the approved GMES Sentinel-3 series of satellites with its operational multi-channel, broader swath, dual view Sea and Land Surface Temperature Radiometer (SLSTR) successor to the AATSR instrument.

The SST future is relatively secure for visible-infrared radiometers on polar orbiting satellites, with the AVHRR on the Metop series and MODIS instruments being followed by the VIIRS-equipped NPP and then NPOESS series. The (A)ATSR series on ERS and Envisat is to be succeeded by the SLSTR instruments onboard the operational Sentinel-3 series. These plans in U.S. and Europe are now supplemented by the routine operations of FY-3 series with its VIRR sensor. The GOES imagers and SEVIRI on MSG provide complementary, frequent repeat imaging, to mitigate the effects of cloud cover.

Of most urgent concern is the future of the all-weather microwave SST capability of the AMSR-E instrument on Aqua. The descoped MIS instrument aboard NPOESS no longer contains a C-band $(6.9 \mathrm{GHz})$ channel, and so the only equivalent successor instrument is the planned AMSR-2 on GCOM-W in 2011 timeframe. The Group for High Resolution Sea Surface Temperature (GHRSST) [38] has emphasised the importance of continuity of both IR and passive microwave observations on polar and geostationary satellites if a robust continuous SST climate data record is to be sustained. Meanwhile, immediate attention should be given to gaining access to the $6 \mathrm{GHz}$ data from the new multi-frequency radiometer instrument aboard the HY-2A satellite scheduled for launch in 2011.

\subsubsection{Ocean Ecology via Ocean Colour Radiometry}

Ocean colour is the wavelength-dependent waterleaving radiance traditionally measured by passive optical multi-channel visible/IR radiometers or spectrometers. This information has traditionally allowed quantification of biological, chemical, ecological, and biogeochemical properties of the open ocean. With appropriate resolution and spectral capabilities, combined with atmospheric and water conditions, ocean colour can also be used to examine the biology, chemistry, and ecology of the coastal ocean and estuaries, and lakes and rivers.

Today, Ocean Colour Radiometry (OCR) data products are required for understanding and monitoring openocean and coastal biological, biogeochemical and ecosystem processes and phenomena. Further, they are used in assessing climate variability and change through improved understanding of biogeochemical cycles (e.g., carbon pools and fluxes) and food web impacts. In addition, OCR products are today increasingly used in management of living marine resources (e.g., fisheries, aquaculture, marine protected areas) and coastal regions (e.g., monitoring of harmful algal blooms and water quality), and for many other socio-economic applications and benefits [10, 11, 39, 40, 41, 42].

Key OCR data products currently in use are phytoplankton Chlorophyll a ( $\mathrm{Chl}$ a), coloured dissolved organic matter (CDOM), particulate carbon, and suspended sediment. Many other products are in development. These near-surface data are assimilated into coupled ocean models containing ecosystem and biogeochemistry modules [43] for improved understanding of the impacts of ocean climate variability and long-term climate change on ocean primary productivity and in carbon-cycle research [44].

OCR sensors whose data are in widespread use presently include SeaWiFS, MERIS on Envisat, and MODIS on Aqua (see [10] for other existing and future sensors). Depending upon successful launches, routine acquisition of quality global data, and open data sharing policies, future continuity in global OCR data may be assured by a combination of the MERSI instrument on China's FY-3A (launched June 2008), OCM-2 on India's Oceansat-2 (launched September 2009), COCTS on China's HY-1 series, OLCI on ESA's Sentinel-3 series, VIIRS on the U.S. NPP/NPOESS (JPSS) platforms, and SGLI on the Japanese GCOM-C. 
Importantly, these sensors in Low Earth Orbit (LEO) are complemented by the Korean plans for the Geostationary Ocean Colour Instrument (GOCI) instrument on the COMS-1 geostationary orbiting satellite, scheduled for launch in 2011. GOCI will demonstrate the benefits of significantly improved temporal frequency imaging of regional coastal, adjacent offshore and inland waters. The more frequent observations from GEO will help mitigate the effects of cloud cover as well as better resolve the dynamic, episodic, and/or ephemeral processes, phenomena and conditions commonly observed in coastal regions.

Much work remains to ensure continuity of climate quality OCR observations, including meeting such challenges as ensuring free and timely access to calibrated data and access to low-level image data products. The development, long-term stewardship and sharing of in-situ databases containing ocean OCR data and derived products of sufficient quality to use for calibrating and validating satellite data products, is fundamental to establishing common approaches to cross-calibrating and merging OCR data across different satellite sensors. Such databases are also required to support data merging efforts into regional and global scientific products. There remains the need for support for continued research and technology development efforts to provide new and improved OCR data streams, algorithms and products, particularly for complex Case 2 waters.

\subsubsection{Sea Ice (extent/concentration/thickness/drift)}

Changes in sea ice extent and concentration have become a crucial indicator of high-latitude response to climate change. However, in order to fully appreciate the variability in sea-ice mass and volume in response to climate variability it is also required to measure the drift dynamics and thickness [20, 45]. The latter two variables are essential in order to partition the role of thermodynamics and dynamic contributions to ice thickness changes, or to quantify net advective fluxes of freshwater in the form of ice [9].

There is a need to continue the existing 28 year allweather record of sea ice data built by the SMMR, SSM/I and AMSR-E multi-frequency passive microwave radiometers, though recently these data have been supplemented by routine scatterometer sea-ice backscatter image data, wide-swath high resolution SAR image data, and altimeter ice thickness data. Currently, a successor to AMSR-E is planned in the form of AMSR-2 on GCOM-W, with the later addition of the MIS instruments on NPOESS (JPSS). During its decade of operation from 1999 to 2009 , the Ku-band SeaWinds instrument on QSCAT made fundamental contributions to sea-ice monitoring with daily global
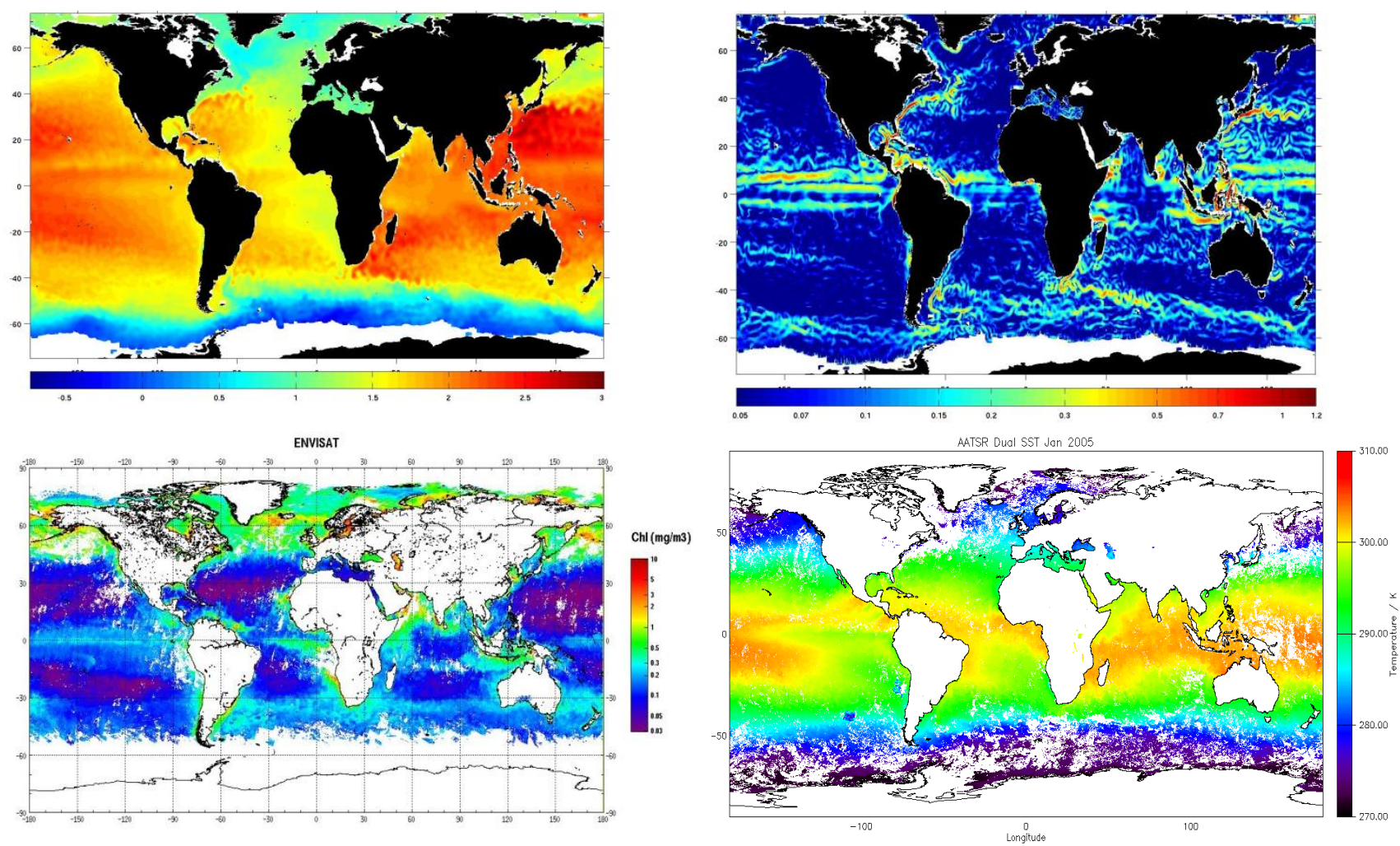

Figure 2. Typical examples of routinely available global composite geophysical products: (upper left) mean absolute dynamic topography - scale in metres; (upper right) geostrophic currents - scale in $\mathrm{m} / \mathrm{s}$; (lower left) Chlorophyll a ocean colour; (lower right) sea-surface temperature. 
coverage at a resolution compatible with passive microwave image data. The Oceansat- 2 satellite with its SeaWinds-like Ku-band scatterometer will hopefully help provide needed continuity until a U.S instrument successor is flown.

ASCAT, on the 15 year series three successive Metop satellites, shall continue the supporting C-band scatterometer timeseries, while the ASAR on Envisat and Radarsat- 2 wide swath instruments have planned operational successors in the form of Sentinel-1 and Radarsat-3, respectively for sea-ice monitoring. Meanwhile, CryoSat-2 will advance beyond Envisat's RA-2 altimeter with high along-track resolution (approx. 300m), and will be followed shortly afterwards by the SRAL on the Sentinel-3 operational series. While ICESAT has also verified the ability to obtain accurate ice thickness profile information, the limitations on laser lifetime had restricted its operation to short data acquisition intervals. As of October 11, 2009, the last remaining laser onboard ICESAT stopped functioning. Since this time, no new science data have been returned from the GLAS instrument. The planned ICESAT-2, currently foreseen in the NRC Decadal Survey [46], would also potentially allow combination of the SRAL radar and laser based thickness retrieval techniques for reducing uncertainties in ice thickness due to snow loading.

\subsubsection{Salinity (SSS)}

Ocean surface salinity (SSS) is a critical variable for constraining evaporation minus precipitation (E-P) or net ocean-atmosphere moisture flux, for understanding the impact of river freshwater outflow on circulation [47], for mapping frontal variability, and for specifying the surface buoyancy forcing in the upper ocean [12]. Meanwhile, the global satellite skin measurement will be beneficial in tying Argo (Array for Real-time Geostrophic Oceanography) sub-surface salinity, temperature and depth information to the existing surface measurements by the moored networks, in order to better understand the role of salinity on ocean circulation.

One of the principal challenges outlined at OceanObs'99 [27] and in [25] was the global observation of mean sea surface salinity (SSS) to a threshold accuracy of $0.2 \mathrm{psu}$ at $200 \mathrm{~km}$ scale at monthly time intervals. The Soil Moisture and Ocean Salinity mission (SMOS) [28] was successfully launched on 2 November, and together with Aquarius (planned for launch in 2010), spearheads the effort to exploit new Lband microwave radiometer capability for observing SSS. It now remains for the scientific and modelling community to exploit the synergy between global satellite and detailed in-situ SSS data to resolve the time and space variability of SST to a degree compatible with the existing SST data such as to improve our understanding of upper ocean processes [12].

\subsubsection{Gravity and Geoid}

The measurement of small variations in Earth's gravity and of the geoid are now recognised to be a fundamental prerequisite to quantifying mass transports in the ocean system, freshwater exchange between land, ocean, ice and atmosphere, and for constraining heat, energy and freshwater cycling through the Earth system [48]. In order to have the basic metrological capability to detect $\mathrm{cm}$-scale changes and mesoscale details in sea-level change using altimeters, access to a precision static geoid or equipotential reference surface of $1-2 \mathrm{~cm}$ accuracy and $100 \mathrm{~km}$ spatial resolution is required [14].

Since 2000 three currently operating missions have been contributing valuable data to meet these needs. CHAMP, GRACE and GOCE satellites have improved knowledge of the static geoid, and GRACE has revolutionised our understanding of the time-variable gravity field. Meanwhile, the GOCE satellite promises to deliver a revolutionary accuracy in the static geoid over the next years of operation [49].

The combination of gravity, altimetric dynamic topography data and bottom-pressure observations now provide an opportunity to make significant progress towards understanding ice-ocean interactions, sea-ice thickness, circulation and mass/freshwater variability of the Arctic and Southern Oceans [8]. Nonetheless, it is necessary to maintain a contiguous timeseries of timevariable gravity, together with bottom-pressure sensors and Argo profilers in order to separate eustatic and steric sea-level change components, and to resolve the critical spatial contribution from ice sheet mass changes and freshwater input. Though the GRACE-2 satellite is identified in the NASA Decadal Report [46], it remains critical to try to maintain a seamless timeseries of GRACE measurements [14]. Thus, the plan to secure a gap-free succession to the GRACE mission remains a key priority.

\subsection{Integration and Synthesis of Satellite Measurements}

During the last ten years, significant advances have been made in terms of new product development and refinement. Further, the level of sophistication in terms of data product use has developed well beyond singlesatellite, single-sensor analyses, in construction and use of global timeseries from multiple or composite data products from different agencies (Fig. 2). These efforts may be broadly divided into the following classes:

- $\quad$ Property or Geophysical variable focus

- Climate issue focus 
Those with geophysical variable focus are characterised by developments to combine similar parameter data from multiple sensor sources and platforms. Typical examples, described in the following section are the development of merged multiple altimeter OST products [50], OCR products [51], and high space-time resolution SST products [52].

By contrast, efforts focused on climate issues have often resulted in combinations of complementary products from multiple sensor sources. An example of such work are studies of sea-level rise using ocean surface topography, Argo drifters, satellite gravimetry, Global Navigation Satellite Systems (GNSS), and tide gauge data from GLOSS [53].

The integration and synthesis of satellite data sets has raised a number of challenges and taught us some significant lessons. These issues remain a thread through the following examples and the following subsections.

\subsubsection{Merged Global Ocean Surface Topography}

The French AVISO altimeter data product distribution centre has been distributing a variety of TOPEX/Poseidon and ERS altimeter data products since 1992 [54]. With the launches of Jason-1 and Envisat in 2001 and 2002, respectively, a new series of altimeter products were developed to fulfill the needs of the ocean community. These products are generated using the Data Unification and Altimeter Combination System (DUACS) at AVISO. DUACS products are intercalibrated at crossover points between different satellite datasets. The resulting gridded data are available in the form of global or regional products in near-real-time or delayed mode, and as high or low resolution geographic maps accompanied by formal mapping errors. These products have been designed to meet a broad variety of scientific applications and non-commercial uses, as well as the data assimilation needs of operational ocean forecasting. Recently DUACS has added Jason-2 data to the merged products, and is preparing for a new generation of SAR altimetry data sets from CryoSat-2, SARAL/AltiKa and Sentinel-3/SRAL.

\subsubsection{Merged Global High-Resolution Sea Surface Temperature Data}

The Global High Resolution Sea Surface Temperature pilot project [38] is an excellent example of an ongoing scientific-based effort that is working hand-in-glove with the operational agencies [52]. A large international consortium has developed and continues to improve an optimal SST product by combination of all-weather microwave and infra-red satellite radiometer data together with in-situ surface drifters. Originally, complementarity between the sampling provided by geostationary and polar-orbiting satellites was not exploited for SST products. By using the intrinsic advantages of each sensor type, and the ability of highfrequency geosynchronous observations to sample cloud-free areas missed by the polar orbiters, the data streams have been combined into a single, optimal high time-space resolution, multi-look product.

The product foundation is the traditional NOAA AVHRR/AATSR polar-orbiter Thermal Infrared (TIR) radiometer data, which has high spatial resolution (1 $\mathrm{km}$ ) and daily repeat coverage, but only clear-sky capability. In order to combat the limited temporal sampling of the polar orbiters, the Meteosat (SEVIRI) and GOES high temporal resolution imager data (at $\sim 5 \mathrm{~km}$ spatial resolution) are used for cloud-free conditions. In order to compensate for the data gaps resulting from the susceptibility of Vis/IR radiometer data to cloud cover, the $\mathrm{C}$-band microwave radiometers on board Aqua (AMSR-E) and TRMM (TMI) are used to obtain night and day SST under all-weather conditions, with the disadvantages of relatively poor $\sim 50-\mathrm{km}$ resolution and lack of retrievals near coasts. The GHRSST project has successfully demonstrated that an optimal SST analysis product can be obtained from combining multiple data sources provided that all error sources for the different data types are correctly accounted for, including cloud screening (for IR) and asynoptic observation times through the diurnal cycle.

GHRSST has set up and operates through international partnerships and national funding several tools that assist users in the application of SST measurements from space. Of particular note is the use of a dynamic high resolution diagnostic dataset (HR-DDS) that allows users to intercompare and analyse satellite SST measurements in near real time for validation and bias estimation purposes [55]. GHRSST also provides a metadata repository with full data set search capability, a match-up database system for quality control and uncertainty estimation, and a long term stewardship and reanalysis facility. These tools form essential components of a user-driven end to end system for use by operational and research teams.

\subsubsection{Merged Global Ocean Colour Data}

The International Ocean Colour Coordinating Group (IOCCG) has been an important driving force towards harmonisation of satellite ocean colour instrument capabilities, algorithms, resulting data products and product use. One important consequence of greater interoperability of data products is the capability to start 


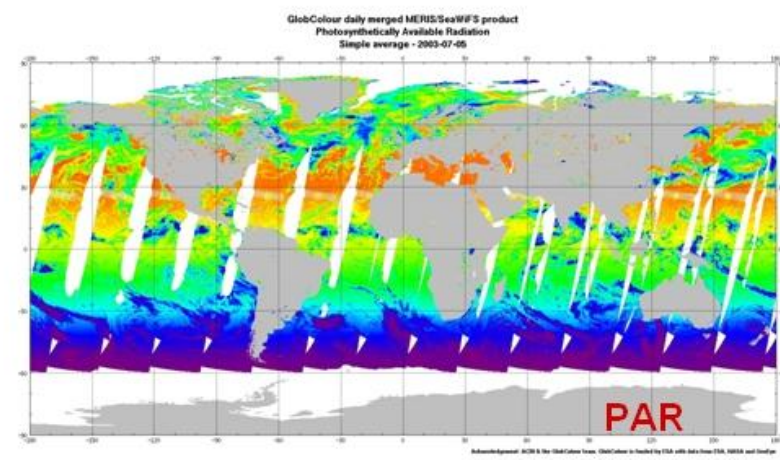

Frouin (2009)

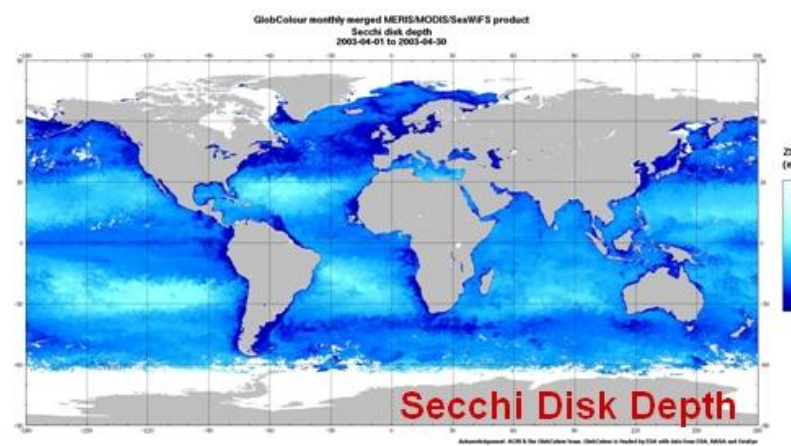

Morel, A., et al. (2007) \& Doron et al (2006)

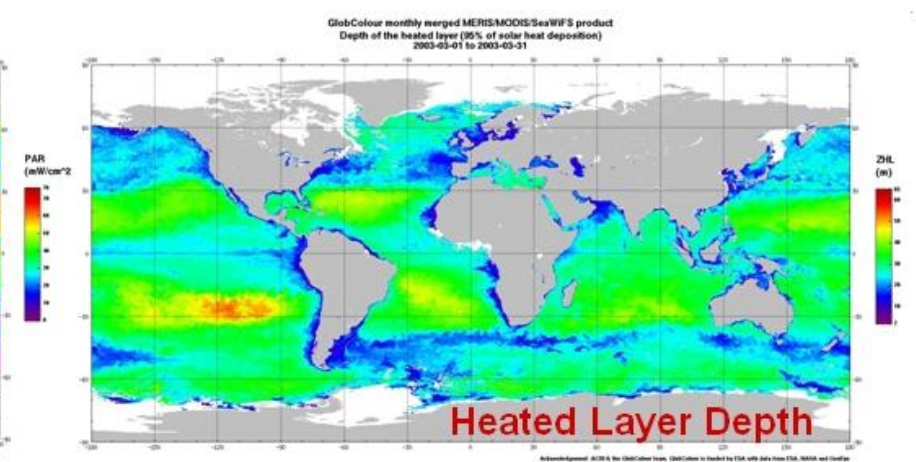

Morel, A., et al. (2007)

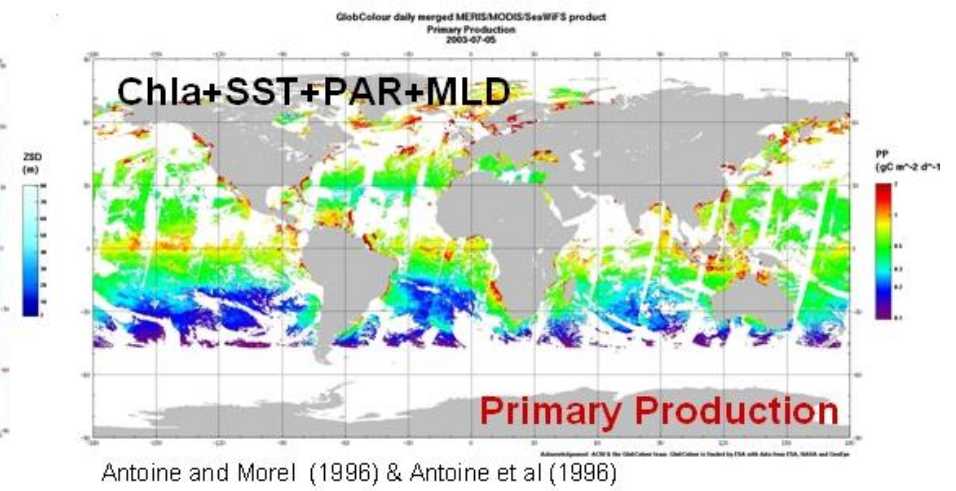

Figure 3. Examples of SeaWifs/MODIS/MERIS synergy products from the GlobColour Project. Panels indicate (upper left) daily Photosynthetically Available Radiation (PAR) from 5 July, 2003; (upper right) monthly merged Heated Layer Depth; (lower left) monthly merged Secchi Disk Depth; and (lower right) daily Primary Production.

to build global multi-satellite OCR datasets to construct climate relevant timeseries that meet global carbon cycle research needs. As a result, the European GlobColour project [51] is one example out of a number of similar efforts initiated to develop a satellite-based ocean colour data set to satisfy this need. Its aim was to satisfy the scientific requirement for a long (10+ year) time-series of consistently calibrated global ocean colour information with the best possible spatial coverage. This has been achieved by merging data from the most capable ocean colour sensors (SeaWifs/MODIS/MERIS).

The GlobColour service distributes a variety of global data sets using well documented and published algorithms, some of which are featured in Fig. 3. These products include chlorophyll concentration, water leaving radiances, diffuse attenuation coefficient, coloured dissolved and detrital organic materials, total suspended matter or particulate backscattering coefficient, turbidity index, transparency, heated layer depth, and cloud fraction and quality indicators. Products are generated on a daily, weekly (8-day), and monthly basis, on a $4.63 \mathrm{~km}$ equal area grid. The global Earth domain is covered with focus on localised diagnostic data set geographic areas for qualification and validation purposes.
Other similar, merged multi-satellite ocean colour data products (from SeaWifs and MODIS/Aqua) at $9 \mathrm{~km}$ grid-spacing are available using the Ocean Colour Time-Series Online Visualization and Analysis system [56]. These products are currently offered at monthly intervals though 8 day products are planned for release in 2010. An easy-to-use, Web-based interface allows online visualisation and analysis of the data.

\subsubsection{Integrated Satellite and In-situ Applications}

Sustained satellite observation time-series have importantly facilitated the transition from single instrument product applications to integrated applications with both research and operational interest. There are also applications that focus specifically on issues of direct societal relevance.

Table 1 contains a summary of some of the principal observing system synergies that may be exploited to address key integrated science themes. The table indicates which specific parameter datasets may be combined to address a particular theme, as well as where specific advances may be foreseen due to new satellite sensors.

For example, Tab. 1 points to the combination of altimeter and gravimetrically-derived geoid data, together with SST and SSS. The global combination of 
the relevant satellite and in-situ data allows the largescale ocean surface topography to be referenced to a precise geoid such that the absolute dynamic topography and large-scale geostrophic (Fig. 2) and mesoscale circulation can be diagnosed [33]. Moreover, further combination with temperature, salinity data and repeat hydrography data allows to quantify eustatic, thermosteric or halosteric contributions to sea-level rise, and to understand the processes driving regional variability in sea-level over time [14, 57].

Other examples are highlighted for instance for wind waves and current (see also new products in section 4.1 below), for surface fluxes [4], ecosystem dynamics, biogeochemistry and coastal zone management, and ocean-cryosphere-atmosphere applications [8].

Integration of satellite datasets with in-situ measurements and models has allowed a number of significant lessons to be learned [16]:

- Data integration and synthesis yield new analysis tools and dynamical frameworks

- Development of multivariate assimilation schemes must be developed to cope with the growing number of continuous time-series, and the growing volumes of new satellite data products

- Significant archives of valuable in-situ data remain to be harvested for verifying measurement uncertainties, and specifying error covariances between key variables

- Assimilation schemes cannot fully exploit satellite time-series without the data being accompanied by measurement uncertainties (e.g. GHRSST single-sensor error statistics)

- Future satellite observing system elements can be optimised with respect to knowledge developed from historical in-situ data.

Figure 4a shows an example of data integration using existing archived AMSR-E data and in-situ drifter data in the region of the Amazon and Orinoco river outflow [47] in preparation for use of SMOS and Aquarius SSS data. These first salinity retrievals from space were performed using AMSR-E radiometer C- and X-band channel brightness temperature data. The resulting salinity image reveal the large-scale spatial structure of the freshwater Amazon plume, extending from about 200 to about $600 \mathrm{~km}$ offshore in this August example. The correlation between the drifter derived near surface current climatology and the SSS patterns derived from the AMSR-E data show the strong relationship between the mean circulation and surface salinity. Meanwhile corresponding coloured dissolved organic matter (CDOM) absorption coefficient based on a monthly composite of SeaWiFS and MODIS products is used as an independent proxy for delineating the spatial extent and patterns of the Amazon and Orinoco freshwater plumes (Fig. 4b). Though links between SSS and

Table 1. Summary of the principal observing system synergies that may be exploited to address key integrated science themes. The required parameters and associated instrument datasets are listed for each theme.

\begin{tabular}{|c|c|c|c|}
\hline Themes & $\begin{array}{c}\text { Required Ocean } \\
\text { Parameters }\end{array}$ & Instruments & Comments \\
\hline $\begin{array}{l}\text { Ocean Dynamic } \\
\text { Topography, Large- } \\
\text { scale Circulation and } \\
\text { Sea Level }\end{array}$ & SSH; SST; SSS; Geoid & $\begin{array}{l}\text { Altimeter; Gravimeter; Vis/IR } \\
\& \mu \text { wave Radiometer }\end{array}$ & $\begin{array}{l}\text { Awaiting } 100 \mathrm{~km} \text { res. GOCE static geoid; GLOSS tide } \\
\text { gauges for calibration }\end{array}$ \\
\hline $\begin{array}{l}\text { Mesoscale } \\
\text { Circulation, Wind, } \\
\text { Waves and Currents }\end{array}$ & $\begin{array}{l}\text { SSH; Wave spectra; } \\
\text { Wind velocity/stress; } \\
\text { SST; Current velocity }\end{array}$ & $\begin{array}{l}\text { Altimeter; Scatterometer; } \\
\text { SAR; Vis/IR Radiometer }\end{array}$ & $\begin{array}{l}\text { Consistent SAR wind, wave and surface current } \\
\text { products yet to be derived; Incomplete examination of } \\
\text { sensor synergies (SAR, IR, Altimeter and Optical) for } \\
\text { advancing interpretation of mesoscale processes }\end{array}$ \\
\hline $\begin{array}{l}\text { Surface } \\
\text { Heat/Moisture/ } \\
\text { Momentum Flux, E- } \\
\text { P and buoyancy } \\
\text { forcing }\end{array}$ & $\begin{array}{l}\text { SSS; Wind Velocity/ } \\
\text { Stress; SST; } \\
\text { Precipitation }\end{array}$ & $\begin{array}{l}\mu \text { wave Radiometer; Vis/IR } \\
\text { Radiometer; Scatterometer }\end{array}$ & SMOS and future Aquarius data \\
\hline $\begin{array}{l}\text { Ecosystem } \\
\text { Dynamics; } \mathrm{CO}_{2} / \\
\text { gas flux; } \\
\text { biogeochemistry; } \\
\text { Coastal Zone } \\
\text { Management } \\
\end{array}$ & $\begin{array}{l}\text { Ocean Colour; SST; } \\
\text { Wind velocity/stress; }\end{array}$ & $\begin{array}{l}\text { Vis/IR Radiometer/ } \\
\text { Spectrometer; } \\
\text { } \text { wave Radiometer; SAR }\end{array}$ & $\begin{array}{l}\Delta \mathrm{pCO}_{2} \text { regional/seasonal covariance (with wind, } \mathrm{SST} \text {, } \\
\mathrm{SSS}, \mathrm{MLD} \text { ) needed from in-situ }\end{array}$ \\
\hline $\begin{array}{l}\text { Ocean-Ice- } \\
\text { Atmosphere fluxes; } \\
\text { ice/freshwater mass } \\
\text { variability and } \\
\text { exchange }\end{array}$ & $\begin{array}{l}\text { SST; Ice extent/ } \\
\text { concentration; } \\
\text { Sea-ice thickness; } \\
\text { Ice-drift velocity; Ice } \\
\text { surface temperature }\end{array}$ & $\begin{array}{l}\mu \text { wave Radiometer; } \\
\text { SAR/Laser Altimetry; } \\
\text { Vis/IR Radiometer }\end{array}$ & $\begin{array}{l}\text { Awaiting CryoSat-2, ICESAT-2; Sentinel-1, Sentinel-3, } \\
\text { and DesDynI }\end{array}$ \\
\hline
\end{tabular}


CDOM are revealed using mixing models and in-situ data, these results indicate for the first time that satellite data can be combined with in-situ data to reveal the synoptic correlation between these two variables in river plume areas. This example illustrates the significant opportunities provided by synergetic use of satellite and in-situ data for investigating dynamics and mixing processes and coupling between physical and biogeochemical processes.

In-situ reference data are absolutely essential for the calibration of some satellite sensors, and for validation of geophysical products. The efforts to merge multisatellite SST products have also demonstrated the importance of establishing the principle of "diagnostic data sets" or databases with common reference in-situ measurements that are used by different Agencies to establish respective measurement system biases [38]. This principle has also been adopted for the purpose of vicarious calibration of OCR measurements using marine optical buoys (e.g. MOBY and Boussole) and validation of ocean colour products in the ChloroGIN (Chlorophyll Global Integrated Network) project [11].

Integration of satellite, airborne, in-situ and model data is also at the basis of a number of unique new operational services established throughout the world over the last decade. All-weather SAR, for instance has, under certain sea states, the capability to provide valuable information on the precise location of surface slicks or oil spills, and ships. When combined with the terrestrial or satellite received vessel-borne transponder system AIS, this provides a powerful tool for assisting verification of illegal dumping and associated counter pollution measures. Meanwhile, applications benefiting from combination of AIS and high resolution SAR data are being developed for use in piracy and marine surveillance, and coastal security and maritime border surveillance applications.

The European Maritime Safety Agency (EMSA) is tasked to contribute to the enhancement of the overall maritime safety system within the European Union. One of its goals is to reduce the risk of marine pollution and to assist Member States in tracing illegal discharges at sea using satellite monitoring. Accordingly, EMSA has developed the CleanSeaNet service [58], a satellite based monitoring system for marine oil spill detection and surveillance in European waters. The service provides a range of detailed information including oil spill alerts to Member States, rapid delivery of available satellite images and oil slick position.

Operational oil spill mapping with SAR is also undertaken nationally in the U.S., Canada, Norway and France. Together with the existing Cosmo-Skymed constellation (currently 3 and soon to be 4 satellites),
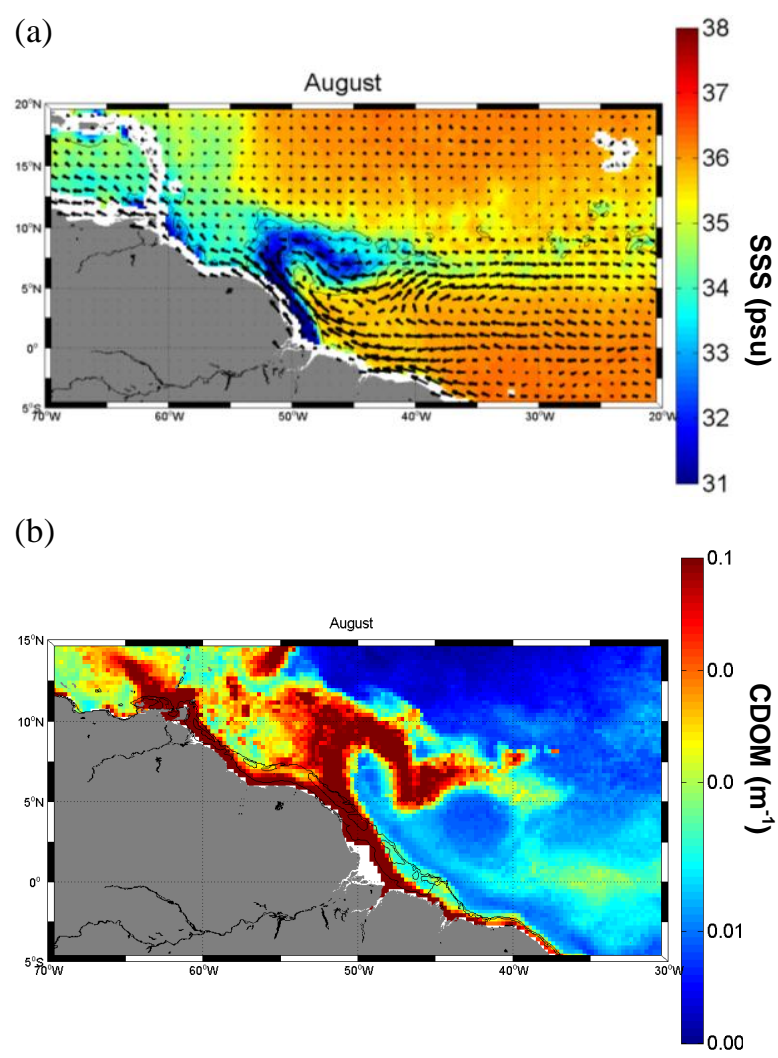

Figure 4. Monthly climatology of (a) AMSR-E derived sea-surface salinity (SSS) combined with drifter-derived near-surface currents; and (b) MODIS and SeaWifs derived coloured dissolved organic matter (CDOM) absorption coefficient. Courtesy N. Reul et al.[47].

and TerraSAR-X, the future GMES Sentinel-1 (two satellites) and RADARSAT Constellation Mission (three satellites), along with perhaps the Japanese ALOS-2 and NASA's DESDynI mission concept, will effectively serve as an operational virtual constellation of SAR satellites. The combined X-, C-, and L-band imaging capabilities of these missions will permit SARderived ocean products to become truly operational and will support a broad range of near-real time user applications.

\subsection{Virtual Satellite Constellations}

In order to properly integrate and optimise the space component of the observing system infrastructure it was recognised by CEOS that an inter-Agency coordinating mechanism must be established. Importantly, this accompanies the recognition that no one Agency can single-handedly fulfill all the key ocean measurement requirements.

Consequently, the concept of virtual, space-based constellations has been developed as a means of more comprehensively addressing the space component of 
GEOSS and as a means of retroactively optimising the existing space infrastructure to meet current needs. A Virtual Constellation (VC) constitutes a set of independent space and ground segment capabilities which when operated in a coordinated manner bring added value and additional benefits. The individual satellites and ground segments can belong to a single or multiple owners. Thus, in effect it is a virtual system that overlaps in coverage in order to meet a combined and common set of Earth Observation requirements. This differs in principle to a real constellation of a single Agency comprising multiple satellites, such as the Italian Cosmo-Skymed constellation of SAR satellites. In this instance the orbits and operations of the individual satellites are specifically designed and optimised to achieve a specific set of mission objectives.

The VC concept builds upon or helps to focus existing projects and activities. Constellation teams provide a unique forum to achieve political visibility and increase mutual benefit among space and other environmental agencies. In particular, they offer opportunities to share experience in the development of algorithms; standardise data products and formats; exchange information regarding the calibration and validation of measurements; facilitate timely exchange of and access to data products from existing and planned missions; and facilitate planning of new missions - ranging from coordinating orbits to optimising observational coverage to sharing implementation of mission components.

The following virtual constellations are currently in progress with support from CEOS space agencies, in consultation with their respective ocean user communities - each with a major objective in support of climate and other user applications:

- Ocean Surface Topography Virtual Constellation $(O S T-V C)$ : designed to ensure continuity of sea surface topographic measurement in accordance with GCOS requirements, for mesoscale circulation and sea level [20];

- Ocean Surface Vector Wind Virtual Constellation $(O S V W-V C)$ : designed to ensure continuity of wind and significant wave height information for operational marine warnings and forecasts, and in accordance with GCOS requirements for data on wind forcing on the circulation of the oceans [20];

- Ocean Colour Radiometry Virtual Constellation $(O C R-V C)$ : designed to provide sustained, calibrated ocean colour radiance measurements from multiple satellites to provide information on ocean biological, ecological, chemical and biogeochemical properties, and that meet climate requirements [10];
- Sea-Surface Temperature Virtual Constellation (SST-VC): is currently in the planning stages and in the process of approval by CEOS. Multi-satellite SST product generation activities already underway in the scientific domain must be secured, sustained and transitioned to an operational environment. The activity will be planned and coordinated by the Group for High Resolution Sea Surface Temperature to achieve full operational status.

Virtual constellations can be designed in principle to provide better coverage, in temporal, spatial, and/or spectral information, and improved data management and dissemination. This can both help improve information products and reduce net costs for operating agencies. With respect to climate missions, the creation and use of constellations potentially provides significant net benefits through:

- Coordinating use of existing systems providing global data;

- Coordinating the analysis of gaps in current operations and future mission deployment plans;

- Improved inter-calibration and validation activities, and development and maintenance of product uncertainty estimates;

- Generating the potential for advanced, integrated products;

- Providing standards for interoperability and facilitating data uptake into models; and

- Provision of routine global coverage for sustained observations and increased redundancy and continuity and overlap amongst missions.

To obtain benefits of the kind that virtual constellations of assets can provide, it is strongly recommended that the research and operational agencies coordinate their development, operations, standards, and products with international partners. In addition to the obvious coordination of observations and ground systems, agencies should incorporate standard procedures including the use of common ground-based and vicarious calibration sites. The establishment of standards-based "best practices" is also seen as a prerequisite - including recommendations for measurements, calibration, validation and adoption of common standards.

The adoption of common requirements and guidelines that address future ocean objectives will ensure that proposed contributions to a Constellation will help satisfy the relevant community needs as well as addressing the GEOSS implementation plan. It will also ensure that all contributions are welcome and 


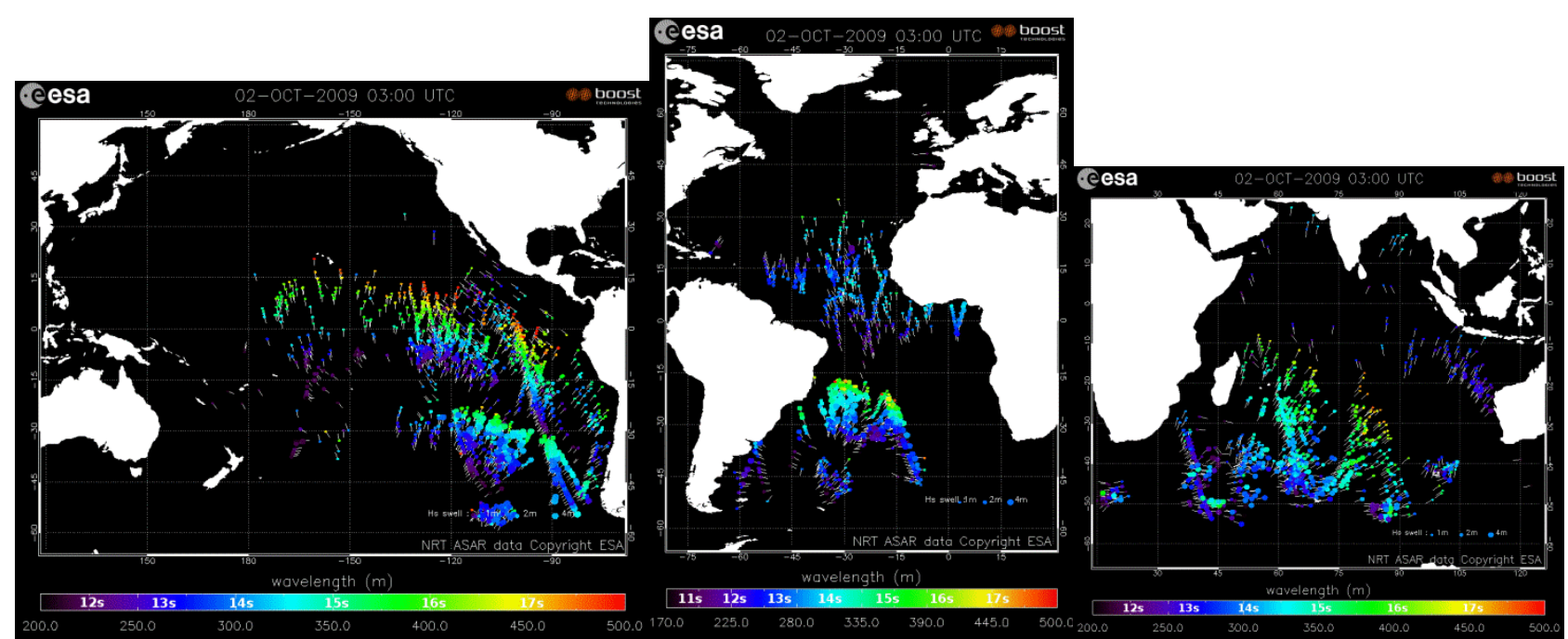

Figure 5. Example of SOPRANO Level 3 operational wave products for the Pacific Ocean; Atlantic Ocean and Indian Ocean for a single day static realisation of propagating swell waves on 2 October, 2009 (03:00 UTC), from global time-series derived from ASAR Level 2 wave mode data (courtesy F.Collard, CLS).

encouraged in order to meet a common objective, and will help facilitate the participation of new contributors.

\section{FUTURE NEEDS AND CHALLENGES}

Given that plans for new satellites are generally approved and fixed on a timescale of a decade or so into the future, we may already chart a robust strategy for optimal use of the approved observing system infrastructure. One imperative is to consolidate and to maximise use and exploitation of new emerging products from ongoing operational missions whose measurements will be sustained. In order to fully benefit from the planned future missions, increasing attention must be given to optimising these missions and their associated data products. New technologies which are just over the horizon will soon find their way into satellite oceanography within the next decade, and it is necessary to anticipate and plan for the use and most beneficial exploitation of these new developments. The future challenges and needs discussed in the section below are therefore split into four sections: new products; infrastructure challenges; data challenges, and new technologies for future missions.

\subsection{New Products}

Over the last few years a number of new products have emerged that have the potential to make a significant impact on the ocean science community. The key attribute of these products is that they are produced using satellite instrumentation which will deliver sustained, uninterrupted near-real time (i.e. within 3 hours delivery) data products over the course of the next decade or more. The following sub-sections outline a few such examples.

\subsubsection{SAR Wave Products}

The development of a new generation of wave products began some 18 years ago, as wave spectra became routinely available from ERS-1 SAR. This foundation has allowed development of methods to investigate the source of swell and to trace the path of swells from wavelength and propagation in order to reconstruct "great circle" propagation paths [59]. More recently, a new generation of basin scale SAR wave products are available from the SOPRANO system [60]. SOPRANO is an operational demonstration of the processing of Near Real Time (NRT) products from Envisat ASAR data (Fig. 5, such that derived wave products are available on the SOPRANO website within three hours of the availability of the source SAR data.

The SOPRANO system processes products as a collection of 2D frequency-directional spectral wave energy density on contiguous blocks of data along the whole SAR image swath. SAR wave product resolution (i.e. the grid spacing between two consecutive estimates of wave spectrum) has been set to $5 \mathrm{~km}$ for image mode products $(100 \mathrm{~km}$ swath) and $20 \mathrm{~km}$ for wide swath products $(400 \mathrm{~km}$ wide swath). On the graphical SOPRANO representation shown in Fig. 5, only the dominant wave system, in terms of the 2D spectral energy, is represented. This is shown in the plots as significant wave height (spot size), dominant wavelength (colour) and direction. Similar information is available on a global scale from the wave mode. In this case, wave spectra are estimated every $100 \mathrm{~km}$ along satellite track and dominant direction used to propagate the observations at a group velocity estimated from the observed wavelength along a great circle ray. Knowledge of the propagation direction and speed allows the processing system to combine several SAR 
observations at different times and locations into a seamless product to enable basin scale swell tracking from the wave source to their final destination. This socalled level 3 product is displayed online as an animated gif over the last 7 days of observations with a 3 hours time step.

The challenge now is to improve the interactions between operational wave forecasting, wave research and satellite ocean wave remote sensing, such that the assimilation of satellite retrievals is fully implemented. Thus there remains a significant work for modellers and oceanographers to find appropriate coupled dynamic modelling framework for assimilation of such data into models. Future operational satellite wide-swath SAR systems such as GMES Sentinel-1 will

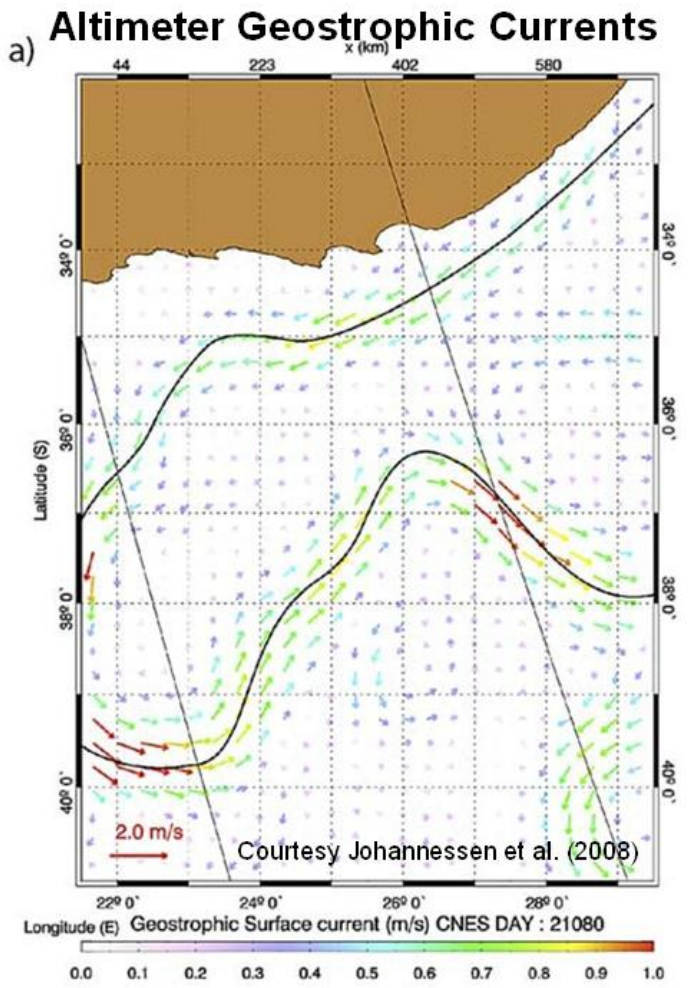

currents and eddies, using imaging SAR systems (see Fig. 6). Pioneering work by [36] and [62] has enabled the radial current component (i.e. along the radar line of sight) to be derived from the Doppler frequency shift caused by the moving ocean surface. Since the Doppler shift results from the combined action of wind, waves and surface currents, both kinematic and dynamic properties of the moving ocean surface must therefore be taken into account to derive a surface current. In [62] a more robust scheme has been developed to consistently examine and remove the dependence of the Doppler velocities on radar parameters and sea-surface radar scattering moving elements. Meanwhile, efforts are underway to assess the uncertainties in the retrievals

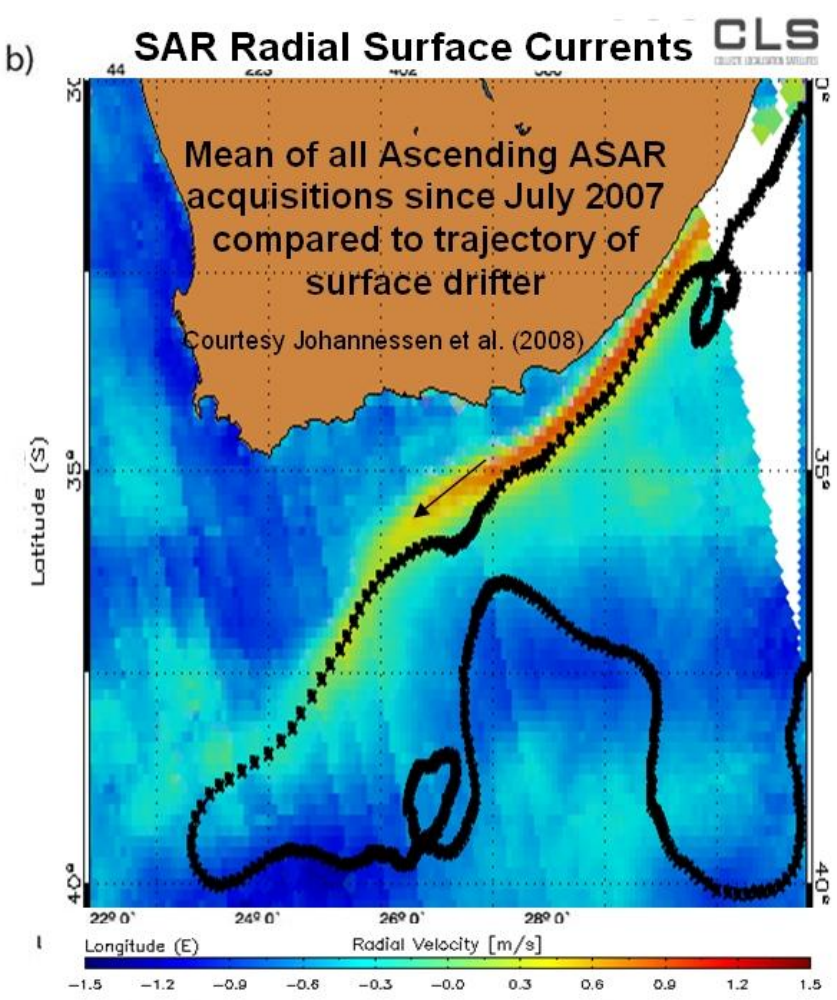

Figure 6. Agulhas current velocities off the coast of South Africa, illustrated using (a) altimeter mean dynamic topography-derived Geostrophic surface currents; and (b) Envisat ASAR image-derived line of sight, radial surface currents (black symbols and arrow indicating drifter trajectory).

provide a sustained global data stream and routine operational products from which to locate and track swells across the Pacific, Atlantic and Indian Oceans in near real time. In the near future, the origin and both the arrival time and intensity of the swells will be systematically and routinely predicted.

\subsubsection{SAR Surface currents}

New processing methods [61] have over the last two years helped refine high resolution retrievals of surface
The results shown in Fig. 6 indicate the mean velocities in the Agulhas current system generated using many accumulated strips of altimeter data and swaths of ASAR data over time. Comparisons of altimeter geostrophic currents in Fig. 6a with the coincident SARderived currents in Fig. $6 \mathrm{~b}$ affirms that routine SAR products will help advance the use of such products in quantitative studies of ocean currents and in operational ocean forecasting. The Agulhas retroflection is traced by drifter trajectory in the right panel in Fig. $6 \mathrm{~b}$. The 
$100 \mathrm{~km}$ wide and opposite directed speed reaching nearly $2 \mathrm{~m} / \mathrm{s}$ with an estimated accuracy of about 0.2 $\mathrm{m} / \mathrm{s}$ and with a maximum shear of about $10^{4} \mathrm{~s}^{-1}$ is reflects predominantly the influence of the Agulhas Current on the Doppler velocity measurement. The same is also valid for the $1.5 \mathrm{~m} \mathrm{~s}^{-1}$ Doppler speed of the Agulhas Return Current. This suggests that it is possible to derive quantitative information of these intense surface currents from the radial Doppler velocity. Using this method in combination with surface drifters and altimeter derived surface geostrophic current could consequently strengthen the ability to study surface current dynamics.

Due to present limitations in the spatial resolution of altimeter-derived mean dynamic topography, such results are considered promising for strengthening the operational use of SAR in quantitative studies of the ocean currents. Combined with surface drifters and altimeter-derived surface geostrophic current, monitoring of the dynamics of intense current regimes may be advanced. Furthermore, as persistent feedback exists between the near surface wind, sea surface temperature and surface current in frontal regions, these new consistent kinematic and dynamic SAR-based observations will also improve studies of air-sea interaction processes in vicinity of strong current regimes.

Advancing the quantitative estimation of surface current dynamics also implies new possibilities to explore the coupling to biogeochemical processes that often occurs through ageostrophic processes along fronts and within eddies, usually well traced by local radar cross-section intensity contrasts.

\subsection{Infrastructure Challenges}

As pointed out by [26] and reiterated by [15], the principal challenge remains to advocate, plan and finance and press for executing the transition of the critical R \& D satellite sensors to operational status. In practice, instead of ad-hoc financing of individual satellites, this means putting in place a structured approach to planning and financing series of several satellites. In this manner, continuity in data is assured by the launch of replacement satellites with equal or improved capability when the data become degraded below an acceptable level of quality. The defining principle which identifies an "operational" series is that the quality of products can also be maintained at a specific level, such that a robust geophysical time-series may be established. However, this presents a paradox in that operational agencies tend to be more wary of assuming responsibility for new requirements or for potential innovation in a measurement.

\subsubsection{Operational vs. Sustained Climate Observations}

Whereas the inclusion of sensors in operational systems in theory provide long-term monitoring data, it also implies significant overhead associated with meeting requirements for high reliability of the data streams and near-real time availability of the products. In the future it is necessary for operational agencies to design this infrastructure sufficiently robustly to meet climate needs, and in order that the rigorous requirements for climate product time-series can be met. From a satellite perspective this means specific attention to tailoring instrumentation to meet climate science needs and to design the missions to fulfill the GCOS climate monitoring principles [20]. The desire to conduct and achieve sustained climate-relevant measurements as part of an operational programme should clearly be balanced with the pragmatic need to achieve a cost-effective result. The example of the GMES Space Component programme may be used as such an approach in which critical climate record needs such as SST have been respected and firmly embedded within the operational requirements.

\subsubsection{Avoiding Duplication \& Achieving optimal time/space sampling}

To obtain the benefits of the kind that virtual constellations of assets could provide, it is strongly recommended that the research and operational agencies coordinate and optimise their orbits and operations with their international partners. Organisations such as CEOS, CGMS (Co-ordination Group for Meteorological Satellite), WMO (World Meteorological Organization) and GEO (Global Earth Observation) must provide tangible support to develop a strategy and formal approach by which to meet this goal. It may be that binding agreements must be made at intergovernmental level in order to foresee satellite orbit optimisation or operations to the extent where loose formation-flying or coordinated operations scheduling and data distribution may be achieved. Only in this manner can virtual constellations truly fulfill the goal of achieving better time-space coverage, better spectral coverage, improved synergetic products, improved data management and dissemination. Similarly, this is ultimately the only way to remove redundancy or to reduce overall costs for operating agencies.

Via broad community consultation, WMO has documented an approach towards design of the optimal space based component of a global observing system with its Vision for the GOS in 2025 [63]. This proposed global framework, developed from the approach of coordinating operational meteorological satellite observations, facilitates the development of individual agencies' plans in a complementary manner. The vision foresees a backbone of operational satellites in 
complementary orbits (geostationary and polar), complemented by contributing polar orbiting $\mathrm{R} \& \mathrm{D}$ satellites. Together this concept builds on the Initial Joint Polar System (IJPS) configuration in which the a.m. and p.m. equator crossing time of NOAA and Eumetsat polar orbits are optimised for most frequent coverage. The vision calls for:

- Contiguous, gap-free geostationary coverage of the globe by ensuring no more than $70^{\circ}$ longitude separation between locations of adjacent geostationary satellites equipped with at least a

(a)

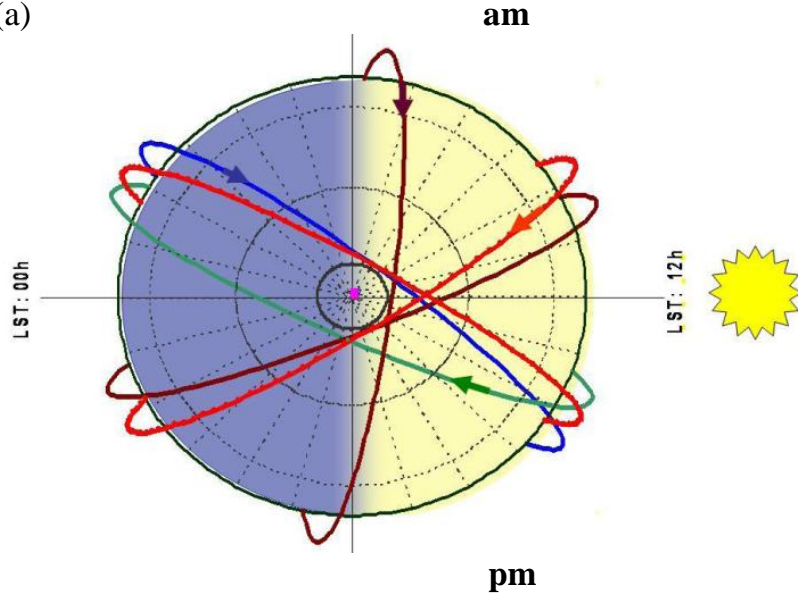

(b)

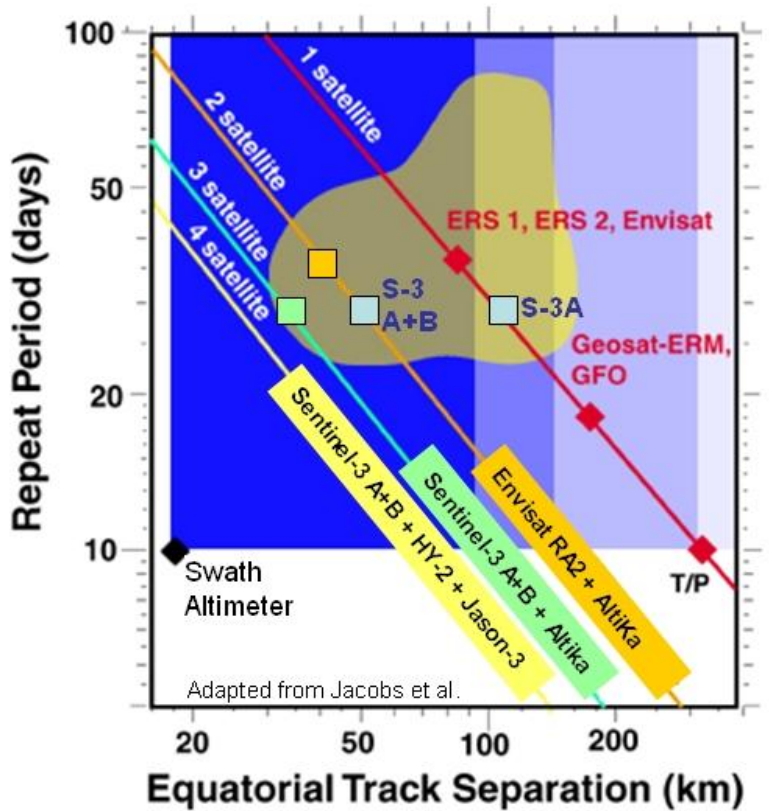

Figure 7. (a) Schematic illustration of use of am and pm polar orbits to optimise time-space sampling of the globe [63]; and 7b. Ideal sampling of mesoscale ocean variability (brown patch) requires a coordinated Virtual

Constellation of several conventional altimeters, including ideally one precise reference mission (tidefree orbit) and more than two in optimised sunsynchronous orbits. standard suite of Vis-IR instruments and new measurement technologies with potentially significant added value;

- Deployment of the operational LEO sunsynchronous polar-orbiting satellites constellation over 3 orbital planes around 13:30, 17:30 and 21:30 Equatorial Crossing Time and including visible, infrared and microwave measurement capability. Some redundancy should be available around these orbital planes, to the extent possible (as shown in Fig. 7a);

- Complementary R\&D satellites acquiring data for research purposes, demonstrating new or improved sensor technology. In so far as possible, delivery of data in near-real-time for operational use is encouraged, though obviously without the guarantee of long-term continuity.

The above scheme helps to avoid spatial gaps in the geostationary coverage at low latitudes, as well as gaps in temporal coverage of the polar orbiting satellites especially around dawn and dusk. It also includes provisions for coordinating altimetry from at least 3 polar orbiting satellites in the context of the CEOS OST Virtual Constellation [3]. The approach recommends an observation strategy relying on at least one highaccuracy reference altimeter mission in an orbit ensuring tidal-alias free data (e.g. Jason type non-sun synchronous $66^{\circ}$ inclined orbit), and at least two additional altimetry systems flying on higher inclination orbits to maximise global coverage (e.g. Envisat/RA or Sentinel-3/SRAL). Such a scheme can be used as a foundation for the OST-VC to engage new partners in ocean altimetry, such as India (SARAL/AltiKa) and China (HY-2), in optimising the orbits of their new altimeter missions to build a more robust collective sampling capability.

Fig. 7b illustrates a useful conceptual tool for optimising the orbits of new altimeter-bearing satellites. The region of interest in terms of mesoscale variability dictates that the equatorial track spacing and repeat sampling interval must be minimised to observe this variability and to globally feed model data assimilation schemes with information characterising the appropriate scales. The sampling capability of any single satellite generally falls on the one-satellite line (with some deviation due to orbit height). The observable spatial scales are greater than the separation of adjacent ground tracks at the equator, and the observable time scales are greater than the repeat period. Thus, the observable space of a satellite is to the upper right of any indicated satellite point. As constellations of pairs of satellites with identical phased orbits are added, such as Sentinel$3 \mathrm{~A}$ and $-3 \mathrm{~B}$, the point moves left onto the two-satellite line and the resulting sampling density improves. Equivalently, if the orbits of different altimeter missions 
were to be fully optimised and interleaved, as may be achieved for similar sun-synchronous orbits, the sampling density and resulting benefits are greater (e.g. Sentinel-3A+B + HY-2 + Jason-3).

The current minimum requirement for a 3 altimeter missions in synchronised orbits is explained by Fig. 7b, given that the 3 satellite line encompasses much of the mesoscale range. In reality, however, Nyquist theory and ground-track sampling requirements dictate the need for much more than 3 altimeter satellites to properly globally observe the mesoscale. Thus, the real challenge is in implementation of such a constellation of altimeters, and in obtaining the agreement of space agencies to optimise their orbits and thus coverage accordingly. This approach must become a future priority for the OST-VC, as well as engaging new agencies in increasing the density of altimeter measurements. Meanwhile, the development of swath altimetry is ongoing as a technical solution that could achieve much smaller time-space sampling scales, as illustrated by the black diamond in the lower left of Fig. 7 [6].

Clearly, it is not only the job of the space agencies to work together towards an optimal observing infrastructure. Periodic reviews of the satellite infrastructure will ensure that gaps and shortcomings can be addressed in a timely manner. Ideally, reviews should be conducted independently of the Space Agencies, to fully assess the value of particular measurements and thus redundancies in the space component of the observing system. Such efforts must engage the modelling community in a structured manner so as to establish coordinate and conduct objective Observing System Experiments (OSE's) that quantify the benefits of all observing system components. Standards and methods should be developed and agreed for sequentially withholding specific measurements in multivariate data assimilation schemes in a controlled manner. This approach allows establishment of the net value of specific measurement types, with appropriate Figures of merit (established also in a relative sense) between different parameters and data types. Similarly, a suitable infrastructure must be established for Observing System Simulation Experiments (OSSE's) so as to allow the space agencies to qualify the full benefit of new R\&D satellite systems during the phase where their feasibility of new concepts is established prior to their approval for development [44]. This method can also provide objective guidance as to the most beneficial new instruments and defining orbital scenarios which maximise the synergies amongst the elements of the composite global observing system.

\subsection{Data Challenges}

As satellite oceanography becomes a more coordinated and collaborative international effort there is an increasing need for agencies to adhere to best practices in order to build global data sets that are accessible, interoperable, comparable, and maximise the potential for integrated products. Having coordinated the infrastructure and operations of satellites in virtual constellations, such an approach will facilitate more rapid uptake of data into models. Some of the most important data product challenges are identified in the sub-sections below.

\subsubsection{Consistency and Homogeneity of Data}

Community-wide progress must be achieved towards ensuring the availability, consistency, homogeneity, quality and usability of satellite derived data products in the next decade [16]. The CEOS Working Groups on Calibration and Validation (WGCV) and Information Systems and Services (WGISS) are working together to solve issues of data access, formatting and product harmonisation. Meanwhile, collaboration between the WGCV [65] and the Global Space based Intercalibration System (GSICS) efforts of the CGMS operational agencies [66] must be fully supported and enhanced to ensure that common methods and standards are applied across the R\&D and operational agencies. Standard calibration and validation methods must be established and common vicarious calibration and validation reference sites identified and supported by the different Agencies.

Recently, a new focus is on the Quality Assurance Framework for Earth Observation (QA4EO) and its implementation. QA4EO underpins the need for a data quality assurance (QA) strategy to facilitate interoperability of satellite systems. This strategy is based upon a set of key operational guidelines derived from "best practices" for implementation by the community [67]. The QA4EO scheme has been completed and endorsed by CEOS and is recommended for implementation and use throughout the satellite oceanography community.

\subsubsection{Calibration, Validation and Performance Monitoring}

As longer-term data sets are constructed for detecting and characterising climate trends, so the requirements for instrument characterisation, calibration and stability assessment must become more stringent. Today acquisition of climate relevant measurements relies on the instrument measurements being benchmarked against absolute laboratory standards, and for the implementation of pre-launch and on orbit calibration 
strategies that ensure the robustness in terms of high accuracy and precision (repeatability) of satellite measurements over their mission lifetimes.

Since pre-launch, sensor calibration can be affected by the shaking and other effects experienced during launch, and the difference between the ground and space environment, suitable on-board calibration reference sources must be implemented, as well as implementation of repeated reference measurements of known external targets with specific well-known, uniform and stable characteristics (e.g. stellar, solar, lunar).

Although the typical design lifetime of most instruments has increased to the order of several years in the case of operational satellites, such nominal satellite lifetimes are insufficient to observe and detect slowly varying climate signals on longer timescales. Thus, it is necessary to compile data from overlapping missions and to cross-calibrate their data. An adequate period of overlap of up to a year is fundamental to removing calibration biases among independent measurements and to establishing residual calibration uncertainties.

The possibility to make time-space collocated observations of an independent reference targets by different satellites on crossing orbits is a means of establishing measurement biases (e.g. altimeter crossovers). Similarly, non-collocated observations of timeinvariant targets such as stable ice sheet plateaux (e.g. Dome-C, Antarctica) are another important method for building up statistical match-up databases for calibration monitoring and for validation of geophysical products derived from the data. Such statistical databases give the ability to calculate time-varying biases and furthermore are absolutely essential to maintain in order to be able to reprocess old data in order to construct long climate variable records from fundamental data records acquired across several different satellite missions. Statistics from comparisons with well-characterised in-situ measurements allow the residual uncertainties in the system to be fully characterised. The planning and design of systematic validation campaigns throughout the lifetimes of the missions are therefore also of great importance.

Harmonisation of calibration and cross-calibration practices is essential to ensuring and maintaining consistency in records. As mentioned in 4.3.1, the QA4EO approach will help in this regard by establishing calibration protocols, in identifying common calibration and validation sites, and by ensuring that essential historical match-up databases or diagnostic data sets are archived and properly maintained. Initial efforts are now underway to share these data available via the CEOS cal/val portal [68].

\subsubsection{Evolution in Data Products}

The multiplication in the number of satellite ocean data products, together with their respective volume and complexity, drives a fundamental need for space agencies to address the following challenges:

- to support community readiness for new missions and data products

- to accompany all products with uncertainty estimates and data quality flags

- to prepare appropriate product manuals and product readers

- to facilitate ease of access and use of products

- to prepare operators and forward models that allow users to more conveniently use and assimilate data

The introduction of new measurement technologies over the next decade also places a considerable demand on the ocean community to cope with these additional complexities. For instance new forms of gridded products (e.g. SMOS hexagonal grid) may make it necessary to rethink how best to assimilate such new products without compromising the quality of the assimilated data via grid transformations.

Equally, the step-wise increase in data volumes with increases in resolution and repetitivity will also confront users who are currently familiar with less demanding data volumes and data rates. So called higher bit-rate sensors will force the user community to adapt to this new environment and they will have to adapt and scale their processing capacity accordingly. An example is the change confronting the altimeter user community, whereby the more traditional low-bit-rate firstgeneration altimetry is about to undergo a dramatic improvement with the introduction of delay-Doppler, or coherent SAR processed data streams from the new second-generation strain of altimeters CryoSat/SIRAL and SARAL/AltiKa. An order of magnitude increase will take place in along-track resolution from tens of kilometres to hundreds of metres; however, it implies a significant accompanying challenge in the form of increase in data rates, data product sizes and volumes.

The scientific benefits of one-dimensional SAR altimetry is clear, with the potential of much greater along-track resolution, greater precision and less sensitivity to sea state [4] by comparison to traditional measurements. Moreover, the combination holds great promise for observations of the sub-mesoscale as well as the potential for a significant contribution to the emerging field of coastal altimetry [13]. The continuity in these measurements is already assured by the operational SRAL altimeters on Sentinel-3 [64]. 
The transition to operational SAR altimetry implies that a paradigm shift must take place in the use of altimetry data. It is critical that the space agencies support the community in quickly adapting to this change, since a third-generation of wide-swath altimeters such as the SWOT Decadal mission concept [6] is considered by U.S./France for flight towards the end of the decade. Mission concepts like SWOT will require that users have not only mastered the ability to cope with these new styles of products, but also that appropriate dynamical frameworks are successively developed for data assimilation. This requires first to prepare for assimilation of high-resolution along-track data, and then ultimately for two-dimensional high-resolution swath altimetry to be assimilated into coupled models.

\subsubsection{Data Delivery}

Given the challenges described above, it is imperative that the space agencies converge on product format standards which facilitate ease of use (e.g. NetCDF), as well as develop simple, robust data delivery mechanisms. To maximise the use of scientific products one must allow free, open and easy access to data via product ordering interfaces or online catalogues. In the context of operational products the operational agencies should equivalently seek to maximise product use and benefits by data retransmission using BUFR and the MetCast capability.

\subsection{New Technical Capabilities}

Within the next decade, a number of new satellites will be launched and are expected to start producing new and complementary data streams. Meanwhile there are a number of existing technologies that may find added value in new orbital configurations or new or emerging technologies that are being proven for space demonstration. The final concluding sections below outline these issues.

\subsubsection{New Missions}

A new generation of geodetic missions has been established with the CHAMP (2000), GRACE (2002), and GOCE (2009) missions. The GOCE gravity mission, with its fundamentally new gradiometer instrument, began its first 6 month uninterrupted measurement operations phase at the end of September 2009. GOCE will complete its first complete gravity mapping phase in spring 2010, and these data are expected to contribute to a new improved global static gravity field and geoid with unprecedented precision and spatial resolution [14]. Together with ocean and sea ice altimetry, GOCE data [69] will help to make a revolutionary step forwards, allowing absolute dynamic topography to be calculated on a $100 \mathrm{~km}$ scale and for more accurate ice thicknesses to be calculated as a consequence of the combination of a precise geoid and precise surface elevation data.

The successful November 2009 launch of the SMOS mission [70] makes a significant new addition to the arsenal of complementary ocean remote sensing capabilities. Together with Argo sub-surface float data, SMOS measurements will be invaluable for capturing the global distribution of SSS. Notably SMOS will be closely followed in 2010 by Aquarius [12] and together these data will help to provide an additional constraint on the surface boundary condition in coupled ocean and operational NWP models.

In the context of wind and wave data, the Chinese (CNSA) and French (CNES) Space Agencies are in the process of jointly developing the Chinese-French Oceanic SATellite - or CFOSAT [71] satellite mission (with a planned 2013 launch). The primary objective of CFOSAT is to monitor at the global scale the wind and waves at the ocean surface in order to improve wind and wave forecast for marine meteorology (including severe events), the ocean dynamics modelling and prediction and to improve fundamental knowledge on surface processes linked to wind and waves. For this purpose, CFOSAT combines two radar instruments: an innovative new conically scanning, multi-beam wavescatterometer spectrometer (Surface Waves Investigation and Monitoring instrument - SWIM) supplied by CNES, and a wind scatterometer (SCAT) supplied by CNSA. By providing spectral information on waves and surface statistics, a key objective of CFOSAT is to estimate the influence of sea-state on surface fluxes. Recent moves in meteorological centres to couple the atmospheric and wave models, gives the opportunity to take into account the effects of waves on boundary layer processes. In this manner, forecast models may benefit from CFOSAT observations of wind and surface waves.

With a launch in early 2010, CryoSat- 2 promises to provide continuity to the existing high-latitude altimetry timeseries provided by ERS-1/-2 and Envisat [9]. CryoSat's SAR Interferometric Altimeter (SIRAL) promises to revolutionise traditional altimetry, and will demonstrate for the first time high along-track resolution (i.e. $250 \mathrm{~m}$ sampling). This additional capability gives the possibility to profile the elevation of sea-ice floe surface elevations, and to accurately reference them to the sea-surface to yield sea-ice thickness data. In addition, the altimeter will be used on a best-effort basis for open ocean altimetry measurements, and the data will be fed into the DUACS system (see section 3.2) to be merged with other altimeter data. 
Importantly, the use of CryoSat SAR mode over ocean paves the way for use and exploitation of high resolution altimetry data in the coastal zone [13] and will help prepare for the operational SAR altimeter data to be provided by Sentinel-3 in 2013. Importantly, the advances brought by CryoSat- 2 will be complemented by the new AltiKa Ka-band SAR altimeter provided by CNES to the Indian SARAL mission. This mission will be an important new demonstration of $\mathrm{Ka}$ band capabilities over the ocean. Meanwhile, this mission will have the capability to reduce altimetry sensitivity to the ionosphere, whilst pioneering a new class of smaller altimeter for the future of ocean altimetry. into operations. Subsequently, the NPOESS (JPSS) series will maintain operational continuity for these and other data sets.

Similarly, at the European level the ESA efforts towards development of the GMES Space Component missions will also bring operational continuity to data-streams from instruments currently flying on ESA's Envisat mission. The Sentinel-1A satellite, planned for launch in 2012, and later accompanied by its operational partner Sentinel-1B will both carry operational successors to the Advanced SAR (ASAR) instrument, whilst Sentinel-3A (planned 2013 launch) and its operational partner

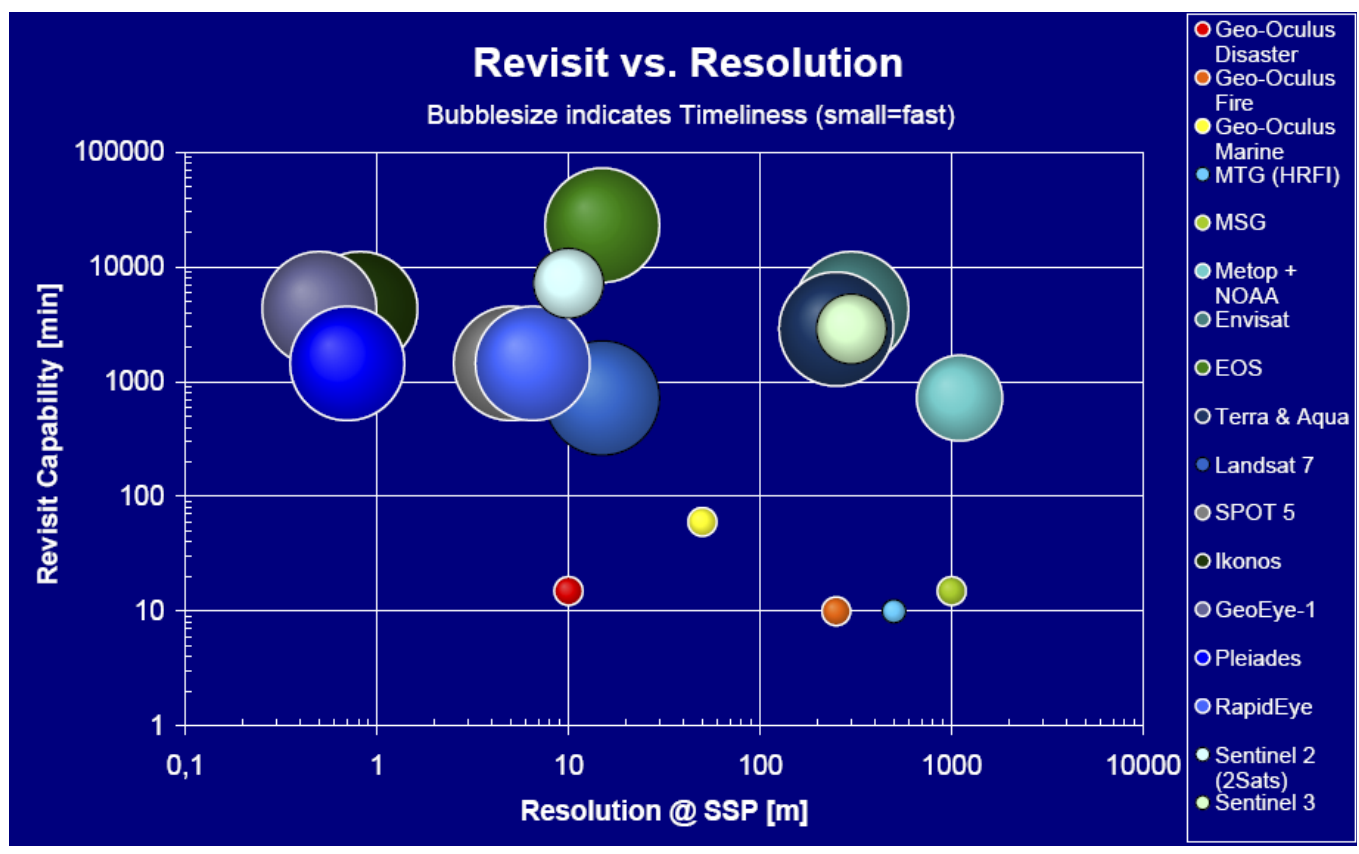

Figure 8. Bubble plot indicating time-space sampling capabilities of optical satellites with Vis/IR instruments, highlighting the push towards spatial resolutions of $<100 \mathrm{~m}$ with a revisit of $<15$ minutes from Geostationary orbit with the Geo-Oculus concept (courtesy Astrium GmbH). Bubble size indicates timeliness (small=fast).

Continuity and operationalisation of ocean colour and sea-surface temperature data streams becomes an important theme of the next several years [15]. The NPOESS Preparatory Project (NPP) is a U.S. mission with a planned launch in 2011, and includes the VIIRS sensor to provide sustained observations for monitoring of global sea-surface temperature as well as ocean colour radiometry data. The latter were intended to be of climate quality and a bridge between the MODIS measurement series initiated by EOS Terra and Aqua and the NPOESS (JPSS) series of satellites beginning in the 2014/15 timeframe. However, concerns have been raised regarding VIIRS spectral performance and OCR data quality from NPP [34]. As part of broader international partnerships and constellations for SST and OCR measurements, the NPP mission will provide operational agencies early access to operational data of the kind anticipated from VIIRS on NPOESS (JPSS) in $2014 / 15$, thereby aiding the transition of VIIRS data
Sentinel-3B will each carry the SRAL altimeter and the SLSTR and OLCI instruments, which promise to provide continuity to the RA2, AATSR and MERIS instruments, respectively [72]. Together these operational missions will deliver time-space collocated instrument data for long-term continuity in sea-ice and ocean wave products, ocean surface topography, ocean colour, and sea-surface temperature data. Along with the continued Metop satellite series with its ASCAT scatterometer, and the planned Jason-3 altimeter, the NPOESS and GMES operational systems help establish the data backbone for the operational oceanography capability for the future.

\subsubsection{New Orbits}

\section{Coordinated Formation Flight}

From a practical standpoint, the existence of constellations has been demonstrated to have become crucial for Earth Science over the course of the last 
decade. The constellation of atmospheric satellites known as the "A-train" has demonstrated the benefits of closely time-spaced, collocated series of multiple measurements from different platforms. Meanwhile, the same 'formation flight' model should be applied in ocean sciences in the future to achieve more direct synergies amongst measurements from platforms of different agencies. Nonetheless, the challenge remains to accomplish the inter-Agency coordination within each of the virtual constellations to facilitate tandem operations between satellites controlled by different Agencies. This issue raises real questions about the operational requirements needed to govern coordinated formation flight of different platforms.

\section{Geostationary Ocean Colour}

The network of existing geostationary meteorological satellites (e.g. GOES, MT-SAT, and MSG) demonstrates that international coordination efforts are needed to meet the global coverage requirement for essential data for numerical weather prediction (NWP) and other applications. The capability of geostationary satellites to deliver frequent repeat images and essential products (presently including SST), at intervals of 1560 minutes, is clearly of particular interest and utility to coastal ocean biological, biogeochemical, and ecological research and applications, considering the limited temporal revisit of polar-orbiting satellites (see Fig. 8). As recommended in the IGOS Coastal Theme Report [29], the first steps are being made toward a coordinated multi-national network of geostationary and hyperspectral (see section 4.4.3) ocean colour sensors with the combined capabilities (i.e. spatial, temporal and spectral resolution) to improve global observations of the coastal ocean.

For regions or periods with frequent and abundant cloud cover, having suitable sensors in geostationary orbit could deliver a significant improvement in ocean colour radiometry coverage. Analysis of cloud statistics from existing geostationary meteorological imager data in such regions illustrates that an improvement can be achieved from a few clear images per month to a few clear (composite or singular) images per week, and potentially up to multiple useful acquisitions per day in many regions. The benefits of improved frequency of sampling include the possibility of following tidal, diurnal, or episodic events at the scale of hours (e.g. growth rate of red tides, phytoplankton blooms, and dissemination of sediments). Other potential benefits and applications include more robust aerosol characterisations and atmospheric corrections, as well as improving the match between the temporal scale of satellite observations and those captured by models.

Until now, the spectral bands and spatial resolution of geostationary satellite sensors have not been optimised specifically with coastal ocean applications in mind. Recognising these limitations, space agencies are now responding to increasing demand for information to meet the data requirements of coastal marine management and water directives. For example, the 2010 launch of the Korean Space Agency's (KARI) COMS-1 satellite [73] with the GOCI sensor will help evaluate and demonstrate the benefits of geostationary ocean colour radiometry. The aim of the GOCI observations includes monitoring of the marine environment in the vicinity of the Korean peninsula to permit analysis of the short-term and long-term change of the marine ecosystem. This mission provides strong assets for synergies with current and planned polarorbiting ocean colour missions, and will for the first time allow sampling of the highly dynamic processes of coastal ecosystems as well as demonstrate the benefits of combined LEO and GEO satellite data for marine and coastal zone applications.

The IOCCG has likewise responded by establishing a Working Group on "Ocean Colour Observations from the Geostationary Orbit" to establish the associated needs and evaluate present and planned capabilities [74]. Based on the experience of the European development of the instrument for COMS-1, CNES and ESA are currently pursuing concept studies for the GEOCO and Geo-Oculus concepts (see section 4.4.3), respectively. In addition to the European developments, NASA have also reviewed various geostationary ocean colour mission concepts, with the GEO-CAPE mission identified as a priority within the Earth Science and Applications from Space Decadal Survey [46]. The latter initiative is viewed as critical to mitigate the discontinued plans for GOES-R to have Hyperspectral Ocean Colour sounder capability (i.e. HES-CWI instrument). Meanwhile, the latter initiative addresses both coastal/oceanic and atmospheric high frequency temporal observing requirements, and would allow for useful synergies across these different domains in support of both research and applied users (e.g., EPA and NOAA).

One important aspect of these collective developments is that such multi-functional sensor capabilities will provide an improved ability to address the complex political framework of ongoing national or multinational efforts such as the European Global Monitoring for Environment and Security initiative, as well as international treaties and European and national directives, policies and protocols. Meanwhile, synergies with existing international Earth observation systems and missions in the context of GEOSS, like NPOESS (JPSS), the GMES Sentinels, and post-EPS are critical to the justification for the ultimate development of a global geostationary environmental constellation. 
Highly-Elliptical Orbit for High-latitude Processes Without geostationary coverage at latitudes north of around $55^{\circ} \mathrm{N}$, the ability to observe the high-latitude oceans is presently limited to the overpass times of polar-orbiting satellites. Whilst the operational missions orbit $\sim 14$ times a day, their inability to make synoptic observations at a higher revisit frequency limits the ability to study sub-daily processes at large scale. Recently, a number of new experimental mission concepts are under development to pave the way towards future polar operational missions. The Russian Arktika and Canadian Polar Communications and Weather (PCW) satellite mission concepts are both planned in highly elliptical orbits (HEOs) and each comprising pairs of satellites with the ability to alternately dwell over the polar region - providing quasi-permanent high latitudes coverage (i.e. above the latitudinal limit of current geostationary satellites) using packages of standard meteorological sensors together with sensor capabilities relevant to polar snow and ice. Meanwhile, a valuable additional benefit would be the possibility for establishing a robust satellite communications link to in-situ networks.

\subsubsection{Emerging New Technologies}

Progressive technology development and miniaturisation of instrumentation over the next decade will undoubtedly lead to instrumentation with new capabilities as well as smaller and more cost-effective satellites. With the push towards higher resolution and more frequent global observations the principal problem becomes data volumes. Although moves may have to be made to institute on-board pre-processing to reduce data volumes, the highest priority is attached to the need for improved data downlink capability to allow higher resolution data to be successfully transmitted to a ground receiving station. Otherwise, the following emerging new technologies hold future promise for ocean remote sensing:

- dual-frequency scatterometry

- advanced swath altimetry

- GNSS-Reflectometry

- high-resolution geostationary, hyperspectral, and passive/active ocean colour

- advanced time-variable gravity mission

\section{Advanced Scatterometer}

CNES, ESA, JAXA and NASA have been conducting studies to investigate potential concepts for the next generation scatterometer instruments. The collaborative CNES and Chinese CFOSAT (see section 4.4.1) with its innovative rotating fan beam scatterometer pioneers a new kind of instrument. Meanwhile, JAXA and NOAA are studying the flight of a NOAA dual-frequency scatterometer (DFS) system to be flown on JAXA's GCOM-W2 and -W3, launching around 2016 and 2020 respectively. DFS is a dual-frequency, real aperture $\mathrm{Ku}$ and C-band pencil beam scatterometer to be accommodated alongside the AMSR-3 radiometer for independent rain contamination correction. The National Research Council (NRC) Decadal Survey recommended that NOAA capitalize on NASA's successful QuikSCAT and provide the nation with a continuing series of operational scatterometers. The DFS on GCOM-W2 and W-3 will satisfy this recommendation, and will do so at a cost far less than that associated with NOAA implementing two dedicated missions that must include the cost of both the satellite and its launch.

ESA is studying various options for a successor to Metop/ASCAT in 2018, with the priority to increase swath width. Finally, the Extended Ocean Vector Wind Mission (XOVWM) system was recommended by the National Research Council [46] as the next generation scatterometer system. The XOVWM concept has a pencil-beam scatterometer with an $1800 \mathrm{~km}$ swath and uses SAR processing to achieve $<5 \mathrm{~km}$ resolution. It features collocated $\mathrm{Ku}$ - and $\mathrm{C}$-band beams to improve the capability to recover high wind speeds in tropical cyclones, and also includes an X-band pencil beam radiometer for improved rain corrections.

\section{Advanced swath altimetry}

NASA and CNES are jointly studying an advanced swath altimeter concept called the Surface Water and Ocean Topography mission. The primary SWOT instrument is an interferometric altimeter with heritage from the Shuttle Radar Topography Mission, and the former Wide Swath Ocean Altimeter concept [6]. Its near-nadir viewing instrument uses two Ka-band SAR antennae at each end of a boom to map a $120 \mathrm{~km}$ wide swath. Interferometric SAR processing of the returned pulses and then spatial averaging over areas of $1 \mathrm{~km}^{2}$ would result in a height precision of the order of centimetres over the ocean surface.

A promising new ESA swath altimeter concept termed "Wavemill" [75] employs offset multibeam antennae and SAR interferometric processing to provide combined swath altimetry and direct measurements of two-dimensional surface current velocity vectors. Costeffective solutions for direct recovery of accurate surface current velocities remain of high priority. Meanwhile, the combination of swath altimetry with a spatial resolution of $300 \mathrm{~m}$ and height accuracy of several centimetres, with current measurements would be ideal for characterising mesoscale and sub-mesoscale processes in the coastal zone.

\section{GNSS-R}

Techniques to exploit so-called "signals of opportunity" from Global Navigation Satellite Systems (GNSS) have matured significantly over the last decade [76]. This 
approach benefits of the signals available in the near future from over 160 GNSS satellites from the U.S. GPS, Russian GLONASS, European GALILEO, Chinese COMPASS and Indian INSS global navigation satellite systems. The fact that the GNSS systems are likely to exist for several decades makes this concept worth investigating for long term ocean observations.

Recently, the UK's Disaster Management Constellation satellite (UK-DMC) has demonstrated the possibility of exploiting reflected signals using the technique known as GNSS Reflectometry (GNSS-R). Published results indicate the capability to derive sea-state relevant information in the form of directional Mean-square slope (MSS) of the sea surface [77]. Given the increasing maturity and status of GNSS-R, it has become feasible to foresee a more comprehensive spaceborne demonstration of this capability in the next decade. Various options exist, such as the possibility of in-orbit demonstration from either the International Space Station, or free-flying satellites such as the IRIDIUM constellation. Notably, UK-DMC results have shown the potential to deliver high spatial and temporal sampling, and therefore offer a complementary way to observe wind and waves by means of a modest instrument.

GNSS-R altimetry concepts studied by ESA such as the PARIS in-orbit demonstrator, indicate the further possibility to augment the global coverage of the existing altimeter constellation - albeit at lower accuracy of several $\mathrm{cm}$. The synoptic capability of such a system could be employed to complement existing altimeter systems.

Hyperspectral, Geostationary High-resolution and passivelactive Ocean Colour Measurements

Now that ocean colour radiometry is moving into a new phase of operational maturity, a key challenge is to develop new and improved space-based ocean biology and biogeochemistry measurement capabilities. Key areas of research and development activity span development of hyperspectral ocean imagers, high spatial resolution sensors for geostationary orbit (as introduced in section 4.4.2), as well as lidar measurements for synergetic combination with swath imagers.

The German Environmental Mapping and Analysis Program (EnMAP) hyperspectral mission is currently approved for development for launch in the 2013 timeframe. This mission will provide for the first time hyperspectral ocean colour data at $30 \mathrm{~m}$ resolution. The combination of high spectral and spatial resolution should allow more effective quantification of geochemical, biochemical and biophysical parameters in the coastal zone.
Various space agencies are presently evaluating the feasibility of development of high spatial resolution imaging sensors for geostationary ocean colour measurements. The Indian Space Research Organisation has plans for a High Resolution GEO Imager (HRGEO) while ESA is conducting feasibility studies for the Geo-Oculus mission concept. Geo-Oculus investigates the potential to achieve $10-200 \mathrm{~m}$ spatial resolution geostationary data, with the objective of a 15 minute image refresh interval for the European coastal zone. Whilst considering the standard meteorological applications, the primary marine applications of its multi-spectral visible and infrared imaging are water quality monitoring in respect to European regulations (i.e. European Union Water Framework Directive), together with algal bloom detection and monitoring. Its secondary objectives include oil slick environmental information and European shoreline monitoring (i.e. Erosion / Sediment Transport).

The Aerosol/Cloud/Ecosystems (ACE) NASA Decadal mission concept combines an ocean colour radiometer, polarimeter, backscatter lidar and cloud radar. This unique sensor combination will give the potential to quantify aquatic carbon storage and ecosystem function in response to natural and anthropogenic forcing. Meanwhile, its backscatter lidar will facilitate direct correction for the interfering effect of aerosols (and particles) on the OCR data.

Development of a new generation of ocean colour instrument capabilities is clearly underway, and which, together with the existing sustained global OCR measurements, will advance our understanding of ocean biology, and chemistry and ecology. Assimilation of more refined data products into coupled models is necessary to better reflect the status and evolution of coastal ecosystems. Ultimately, this will help facilitate integration of more comprehensive ecological modules in climate models, to better estimate the air-sea exchange of $\mathrm{CO}_{2}$ and the effects of long-term, deepocean $\mathrm{CO}_{2}$ sequestration.

\section{Advanced Time-variable Gravity}

The GRACE gravimetry mission has made a revolutionary contribution to oceanography and sealevel studies, yielding data on the time-variable geoid, ocean mass redistribution and bottom pressure variations [8, 14]. The NRC Decadal report meanwhile identified GRACE-2 as a high priority [46]. Thus various studies are underway in the U.S. and Europe to find the optimum configuration for a follow-on mission. A preferred satellite solution would be a dual tandem mission with different inclined orbits, and employing a more accurate laser interferometric link. The advantage of a dual tandem mission would be to mitigate the 
effects of tidal aliasing, which currently limit the performance of GRACE [78]. Together with altimetry, Argo and an optimally designed bottom pressure array for resolving shorter time scale processes, GRACE-2 mission can separate the steric (halosteric and thermosteric) and non-steric effects for quantifying changes in ocean circulation and variability.

\section{CONCLUSIONS}

The OceanObs'09 meeting has demonstrated the recognition of the importance of the oceans from a climate standpoint, as well as from societal, economic and security standpoints. Better stewardship of the oceans starts with robust global information. Meanwhile, collecting this information on a global scale and redistributing it to selected sites is exactly what space systems can do and are already doing, for numerical weather prediction and operational ocean forecasting, environmental monitoring, aquaculture, water and climate monitoring, coastal and maritime surveillance and security.

The lead taken by the United Nations, UNESCO, WMO and ICSU, (United Nations Educational Scientific and Cultural Organization, World Meteorological Organization and International Council for Science) in formulating plans for a sustained, climate relevant ocean observing system has been a fundamental underpinning element to progress in developing the current satellite infrastructure over the last decade. Progressive steps have also been taken by the Space Agencies towards meeting the need for global, sustained measurements of essential climate variables, as mandated by the UN Framework Convention for Climate Change and expressed through the GCOS Implementation Plan [20]. Meanwhile, the Committee on Earth Observing Satellites and the Coordinating Group on Meteorological Satellites have been instrumental in globally coordinating the actions in response to the user needs.

Recent European developments towards establishing a dedicated Space Component of its Global Monitoring for Environment and Security programme have laid the first dedicated keystone en route to development and integration of diverse international space systems into the wider global earth observing system of systems. This integrated approach has the potential to deliver data relevant to policy makers, researchers and the taxpayer.

The OceanObs'09 meeting represents an important milestone in terms of establishing the state-of-art in satellite oceanography and baseline in terms of comprehensive documentation of the essential elements of the ocean observing system. On this basis, consolidation of the existing system and further refinement or development of the optimal ocean observing system components can be foreseen.

In spite of the substantial progress, and the extensive use of remote sensing data in the first ocean prediction systems, some significant challenges lie ahead before the satellite component of the observing system can be considered either optimal or complete. Despite progress towards an integrated global ocean observing system, there still remain considerable limitations of the current ocean satellite observing system infrastructure in relation to adequacy of sampling of the real-time ocean state at mesoscale and smaller scales, and on sub-daily timescales. Such observations are of paramount importance in relation to the role of eddies, internal tides, internal waves and inertial motions on physical and biogeochemical processes particularly in the coastal oceans. The primary technology challenge therefore remains to push towards resolving ocean processes at finer time and space resolution such that the error variance in near real time analyses and forecast skill is minimised.

Finally, the implementation of a robust ocean observing system remains a complex question involving many actors, space and non space, users and developers, all of them having different objectives, different cultures, even a different vocabulary. What OceanObs'09 has demonstrated is that dialogue is the best way to develop and achieve a common understanding. The meeting provided an important opportunity to develop a joint vision between the institutions, scientists, and engineers responsible for implementation of the system and achieving the challenges identified for the next decade.

\section{ACKNOWLEDGEMENTS}

The authors are grateful to the reviewers and a significant number of colleagues who made important observations and contributions to the content of the paper. The contents of this article are solely those of the authors and do not necessarily constitute a statement of policy, decision, or position on behalf of their respective organisations/agencies.

\section{REFERENCES}

1. Ward, S (2008). The Earth Observation Handbook Climate Change Special Edition 2008, ESA SP-1315, ESA Communications Production Office, ESTEC, PO Box 299, 2200 AG Noordwijk, The Netherlands ISSN No.: 0379-6566, pp. 265.

2. CEOS Earth Observation Handbook (2010). http://eohandbook.com 
3. Wilson, S. \& Co-Authors (2010). "The Ocean Surface Topography Constellation: The Next 15 Years in Satellite Altimetry" in these proceedings (Vol. 2), doi:10.5270/OceanObs09.cwp.92.

4. Bourassa, M. \& Co-Authors (2010). "Remotely Sensed Winds and Wind Stresses for Marine Forecasting and Ocean Modeling" in these proceedings (Vol. 2), doi:10.5270/OceanObs09.cwp.08.

5. Pouliquen, S. \& Co-Authors (2010). "The Development of the Data System and Growth in Data Sharing" in these proceedings (Vol. 1), doi:10.5270/OceanObs09.pp.30.

6. Fu, L. \& Co-Authors (2010). "The Surface Water and Ocean Topography (SWOT) Mission" in these proceedings (Vol. 2), doi:10.5270/OceanObs09.cwp.33.

7. Le Traon, P., Bell, M., Dombrowsky, E., Schiller, A. and Wilmer Becker, K., (2010). "GODAE OceanView: From an Experiment Towards a Long-Term International Ocean Analysis and Forecasting Program" in these proceedings (Vol. 2), doi:10.5270/OceanObs09.cwp.57.

8. Kwok, R. \& Co-Authors (2010). "Combining Satellite Altimetry, Time-Variable Gravity, and Bottom Pressure Observations to Understand the Arctic Ocean: A Transformative Opportunity" in these proceedings (Vol. 2), doi:10.5270/OceanObs09.cwp.50.

9. Breivik, L. \& Co-Authors (2010). "Remote Sensing of Sea Ice" in these proceedings (Vol. 2), doi:10.5270/OceanObs09.cwp.11.

10. Yoder, J., Dowell, M., Hoepffner, N., Murakami, H. and Stuart, V., (2010). "The Ocean Colour Radiance Virtual Constellation (OCR-VC)." in these proceedings (Vol. 2), doi:10.5270/OceanObs09.cwp.96.

11. Sathyendranath, S. \& Co-Authors (2010). "ChloroGIN: Use of Satellite and In Situ Data in Support of Ecosystem-Based Management of Marine Resources" in these proceedings (Vol. 2), doi:10.5270/OceanObs09.cwp.75.

12. Lagerloef, G. \& Co-Authors (2010). "Resolving the Global Surface Salinity Field and Variations by Blending Satellite and In Situ Observations" in these proceedings (Vol. 2), doi:10.5270/OceanObs09.cwp.51.

13. Cipollini, P. \& Co-Authors (2010). "The Role of Altimetry in Coastal Observing Systems" in these proceedings (Vol. 2), doi:10.5270/OceanObs09.cwp.16.

14. Shum, C. \& Co-Authors (2010). "Geodetic Observations of the Ocean Surface Topography, Geoid, Currents, and Changes in Ocean Mass and Volume" in these proceedings (Vol. 2), doi:10.5270/OceanObs09.cwp.80.
15. Bonekamp, H. \& Co-Authors (2010). "Transitions Towards Operational Space Based Ocean Observations: From Single Research Missions into Series and Constellations" in these proceedings (Vol. 1), doi:10.5270/OceanObs09.pp.06.

16. Chapron, B. \& Co-Authors (2010). "Ocean Remote Sensing Data Integration and Products" in these proceedings (Vol. 1), doi:10.5270/OceanObs09.pp.12.

17. Claustre, H. \& Co-Authors (2010). "Guidelines Towards an Integrated Ocean Observation System For Ecosystems and Biogeochemical Cycles" in these proceedings (Vol. 1), doi:10.5270/OceanObs09.pp.14

18. Escudier, P. \& Fellous, J.-L. (2009). The Next 15 Years of Satellite Altimetry: Ocean Surface Topography Constellation User Requirements Document. CLS.DOS/NT/09.092, 47 pp.

19. Group on Earth Observations (2005). Global Earth Observation System of Systems GEOSS: 10-Year Implementation Plan Reference Document, GEO 1000R, ESA SP-1284, ESA Publications Division, ESTEC, PO Box 299, 2200 AG Noordwijk, The Netherlands ISSN No.: 0379-6566, pp. 210.

20. GCOS (2009). Implementation Plan for the Global Observing System for Climate in Support of the UN Framework Convention on Climate Change, 2010 Update, GCOS - 92, (WMO/TD No. 1219), pp. 153.

21. GCOS, Systematic Observation Requirements for Satellite-Based Products for Climate, October 2004, GCOS - 107, (WMO/TD No. 1338), Sept. 2006, pp. 90.

22. CEOS (2006). Satellite Observation of the Climate System, The Committee on Earth Observation Satellites Response to the Global Climate Observing System (GCOS) Implementation Plan, 54pp.

23. Balmaseda, M. \& Co-Authors (2010). "Role of the Ocean Observing System in an End-to-End Seasonal Forecasting System" in these proceedings (Vol. 1), doi:10.5270/OceanObs09.pp.03.

24. Heimbach, P. \& Co-Authors (2010). "Observational Requirements for Global-Scale Ocean Climate Analysis: Lessons from Ocean State Estimation" in these proceedings (Vol. 2), doi:10.5270/OceanObs09.cwp.42.

25. Lindstrom, E., J-L Fellous, M.R. Drinkwater, R. Navalgund, J. Marra, T. Tanaka, J. Johannessen, C. Summerhayes (2001). An Ocean Theme for the IGOS Partnership, Final Report from the IGOS-P Ocean Theme Team, NASA, 40pp. 
26. Ratier, A. (1999). Space-based observations in the Global Ocean Observing System: the operational transition issue, White Paper, OceanObs'99, San Raphael, France.

27. Johannessen, et al. (1999). Emerging new earth observation capabilities in the context of an ocean observing system for climate, White Paper, OceanObs'99, San Raphael, France.

28. Kerr, Y.H., P. Waldteufel, J-P. Wigneron, F. Cabot, J. Boutin, M-J. Escorihuela, N. Reul, C. Gruhier, S. Juglea, J. Font, S. Delwart, M.R. Drinkwater, A. Hahne, M. Martin-Neira, and S. Mecklenburg, (2010). The SMOS mission: a new tool for monitoring key elements of the global water cycle, Proc. IEEE, Vol. 98(5), doi: 10.1109/JPROC.2010.2043032, pp. $666-687$.

29. IGOS-P Coastal Theme Team (2006). A Coastal Theme for the IGOS Partnership - for the Monitoring of our Environment form Space and from Earth. Final Report, Intergovernmental Oceanographic Commission Information Document No. 1220. UNESCO, Paris, France, 60pp.

30. European Marine Core Service: MyOcean Project. http://www.myocean.eu.org

31. Bahurel, P. \& Co-Authors (2010). "Ocean Monitoring and Forecasting Core Services, the European MyOcean Example" in these proceedings (Vol. 1), doi:10.5270/OceanObs09.pp.02.

32. The U.S. Integrated Ocean Observing System (IOOS). http://ioos.gov.

33. Scott, R. \& Co-Authors (2010). "Satellite Altimetry and Key Observations: What We've Learned, and What's Possible with New Technologies" in these proceedings (Vol. 2), doi:10.5270/OceanObs09.cwp.76.

34. National Research Council (2008). Ensuring the Climate Record from the NPOESS and GOES-R Spacecraft, National Academies Press, ISBN-10:0-309-12184-1, 180pp.

35. CEOS Ocean Surface Vector Wind Virtual Constellation. OSVW-VC

36. Chapron, B., F. Collard, and F. Ardhuin (2005), Direct measurements of ocean surface velocity from space: Interpretation and validation, J. Geophys. Res., 110, C07008, doi:10.1029/2004JC002809.

37. Swail, V. \& Co-Authors (2010). "Wave Measurements, Needs and Developments for the Next Decade" in these proceedings (Vol. 2), doi:10.5270/OceanObs09.cwp.87.

38. Donlon, C. \& Co-Authors (2010). "Successes and Challenges for the Modern Sea Surface Temperature Observing System" in these proceedings (Vol. 2), doi:10.5270/OceanObs09.cwp.24.
39. Stumpf, R., Fleming-Lehtinen, V. and Granéli, E., (2010). "Integration of Data for Nowcasting of Harmful Algal Blooms" in these proceedings (Vol. 1), doi:10.5270/OceanObs09.pp.36.

40. Forget, M., Platt, T., Sathyendranath, S., Stuart, V. and Delaney, L., (2010). "Societal Applications in Fisheries and Aquaculture Using Remotely-Sensed Imagery - The SAFARI Project" in these proceedings (Vol. 2), doi:10.5270/OceanObs09.cwp.30.

41. IOCCG (2008). Why Ocean Colour? The Societal Benefits of Ocean-Colour Technology. Platt, T., Hoepffner, N., Stuart, V. and Brown, C. (eds.), Reports of the International Ocean-Colour Coordinating Group, No. 7, IOCCG, Dartmouth, Canada, 141pp.

42. IOCCG (2009). Remote Sensing in Fisheries and Aquaculture. Forget, M.-H., Stuart, V. and Platt, T. (eds.), Reports of the International Ocean-Colour Coordinating Group, No. 8, IOCCG, Dartmouth, Canada, 120pp.

43. Le Quéré, C. \& Co-Authors (2010). "Observational Needs of Dynamic Green Ocean Models" in these proceedings (Vol. 2), doi:10.5270/OceanObs09.cwp.56.

44. Rienecker, M. \& Co-Authors (2010). "Synthesis and Assimilation Systems - Essential Adjuncts to the Global Ocean Observing System" in these proceedings (Vol. 1), doi:10.5270/OceanObs09.pp.31.

45. IGOS-P Cryosphere Theme Team (2007). A Cryosphere Theme Report for the IGOS Partnership, Final Report, WMO/TD-No. 1405, 100pp.

46. National Research Council (2007). Earth Science and Applications from Space: National Imperatives for the Next Decade and Beyond, National Academies Press, ISBN-10: 0-309-14090-0, 456pp.

47. Reul, N., S. Saux-Picart, B. Chapron, D. Vandemark, J. Tournadre, and J. Salisbury (2009). Demonstration of ocean surface salinity microwave measurements from space using AMSR-E data over the Amazon plume, Geophys. Res. Lett., Vol. 36, L13607, doi:10.1029/2009GL038860.

48. Beutler, G., M.R. Drinkwater, R. Rummel, R. von Steiger (2003), Earth Gravity Field from Space - from Sensors to Earth Sciences. In the Space Sciences Series of ISSI, Vol. 18, Kluwer Academic Publishers, Dordrecht, Netherlands, 2003, 460pp. ISBN: 1-4020-1408-2.

49. Drinkwater, M.R., R. Haagmans, M. Kern, D. Muzi and R. Floberghagen, Obtaining a portrait of the Earth's most intimate features, ESA Bulletin, 133, 4-13, 2008.

50. European Space Agency, Radar Altimetry Products. http://earth.esa.int/brat/html/data/products.html/.

51. European Space Agency, GlobColour Products. http://www.globcolour.info/products_description.html/. 
52. Group for High Resolution Sea Surface Temperature. http://www.ghrsst.org.

53. Nerem, R. \& Co-Authors (2010). "Observations of Sea Level Change: What Have We Learned and What Are the Remaining Challenges?" in these proceedings (Vol. 2), doi:10.5270/OceanObs09.cwp.65

54. AVISO Radar Altimeter Product Distribution Site. http://www.aviso.oceanobs.com/en/data/productinformation/duacs/.

55. High Resolution SST Diagnostic Data Set. http://medserve.noc.soton.ac.uk/mydds/index.php

56. NASA Ocean Colour Online Visualization and Analysis system. http://reason.gsfc.nasa.gov/Giovanni/.

57. Cazenave, A. \& Co-Authors (2010). "Sea Level Rise - Regional and Global Trends" in these proceedings (Vol. 1), doi:10.5270/OceanObs09.pp.11.

58. European Maritime Safety Agency: Clean Sea Net. http://cleanseanet.emsa.europa.eu.

59. Heimbach, P., and K. Hasselmann (2000), Development and Application of Satellite Retrievals of Ocean Wave Spectra. In D. Halpern (Ed.) Satellites Oceanography and Society, Elsevier Science B.V., 5-33.

60. SOPRANO SAR Ocean Products Demonstration site. http://soprano.cls.fr/L3/fireworks.html.

61. Johannessen, J. A., V. Kudryavtsev, D. Akimov, T. Eldevik, N. Winther, and B. Chapron (2005), On radar imaging of current features: 2. Mesoscale eddy and current front detection, J. Geophys. Res., 110, C07017, doi:10.1029/2004JC002802.

62. Johannessen, J. A., B. Chapron, F. Collard, V. Kudryavtsev, A. Mouche, D. Akimov, and K.-F. Dagestad (2008), Direct ocean surface velocity measurements from space: Improved quantitative interpretation of Envisat ASAR observations, Geophys. Res. Lett., 35, L22608, doi:10.1029/2008GL035709.

63. Lafeuille, J., \& D.E. Hinsman, (2007) Re-designing the Space-based Global Observing System, Joint 2007 EUMETSAT Meteorological Satellite Conference and 15th AMS Satellite Meteorology \& Oceanography Conference, Amsterdam, 24-28 September 2007.

64. Aguirre, M., Y. Baillion, B. Berruti and M. Drinkwater, Operational Oceanography and the Sentinel-3 System (2009). Olla, P. (Ed.) Space Technologies for the Benefit of Human Society and Earth, Springer, pp. 75-98. doi:10.1007/978-1-4020-9573-3.

65. CEOS Working Group on Calibration and Validation. http://www.ceos.org/wgcv.
66. Global Space based Intercalibration System (GSICS). http://gsics.wmo.int

67. Quality Assurance Framework for Earth Observation (QA4EO). http://qa4eo.org.

68. CEOS Calibration and Validation Portal. http://calvalportal.ceos.org.

69. ESA Gravity and Steady State Ocean Circulation Explorer mission. http://earth.esa.int/goce.

70. ESA Soil Moisture and Ocean Salinity Earth Explorer mission. http://earth.esa.int/smos.

71. CNES CFOSAT Mission. http://smsc.cnes.fr/CFOSAT/.

72. Global Monitoring for Environment and Security Earth Observation. http://www.esa.int/gmes.

73. Korean Space Agency's COMS-1 satellite. (http://directory.eoportal.org/get_announce.php?an_id=1 0928.

74. IOCCG Geostationary Mission Working Group. http://www.ioccg.org/groups/geostn.html.

75. Buck, C., Marquez, J., Lancashire, D., Richards, B. \& Caparrini, M. (2010). "The Wavemill Concept for Direct Measurement of 2D Ocean Surface Currents" in these proceedings (Annex). doi:10.5270/OceanObs09.

76. Gommenginger, C., Clarizia, M. \& Unwin, M. (2010). "Towards Long-Term Sustainable Observations of Ocean Wind and Waves with GNSS Signals of Opportunity" in these proceedings (Annex). doi:10.5270/OceanObs09

77. Clarizia, M. P., C. P. Gommenginger, S. T. Gleason, M. A. Srokosz, C. Galdi, and M. Di Bisceglie (2009), Analysis of GNSS-R delay-Doppler maps from the UK-DMC satellite over the ocean, Geophys. Res. Lett., 36 , L02608, doi:10.1029/2008GL036292.

78. Visser, P. N. A. M., Sneeuw, N., Reubelt, T., Losch, M. and Van Dam, T. (2010), Space-borne gravimetric satellite constellations and ocean tides: aliasing effects. Geophysical Journal International, 181: 789-805. doi: 10.1111/j.1365-246X.2010.04557.x

79. Lindstrom, E. \& Co-Authors (2010). "Research Satellite Missions" in these proceedings (Vol. 1), doi:10.5270/OceanObs09.pp.28 